Sear ches for new i nt er st el I ar nol ecul es, i ncl udi ng a tent at i ve detecti on of azi ri di ne and a possi bl e detecti on of propenal

\begin{tabular}{|c|c|}
\hline 著者 & $\begin{array}{l}\text { D CKENS J. E, I RVI NE W M, NUMELI N A, MOLLENDAL } \\
\text { H, SAI TO S, THORW RTH S, HUALMARSON A, OH SH } \\
\text { M }\end{array}$ \\
\hline $\begin{array}{l}\text { jour nal or } \\
\text { publ i cat i on title }\end{array}$ & $\begin{array}{l}\text { Spect r ochi mi ca Act a - A - Nol ecul ar and } \\
\text { Bi ondl ecul ar Spect r oscopy }\end{array}$ \\
\hline vol une & 57 \\
\hline nunber & 4 \\
\hline page $r$ ange & 643660 \\
\hline year & 2001- 03 \\
\hline URL & ht t p: //hdl . handl e. net /10098/1574 \\
\hline
\end{tabular}




\title{
Searches for new interstellar molecules, including a tentative detection of aziridine and a possible detection of propenal
}

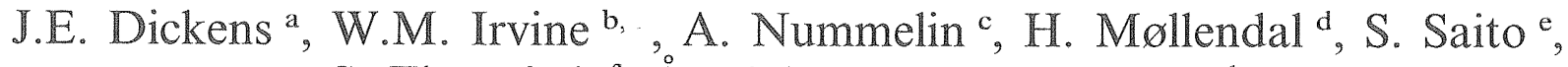 \\ S. Thorwirth ${ }^{\mathrm{f}}, \AA$ Hjalmarson $\mathrm{g}, \mathrm{M}$. Ohishi ${ }^{\mathrm{h}}$ \\ a Jet Propulsion Lab., MS 169-506, 4800 Oak Grove Dr., Pasadena, CA 91109, USA \\ ${ }^{\circ}$ Department of Astronomy, 619 LGRT, University of Massachusetts, Amherst, MA 01003, USA \\ ${ }^{\mathrm{c}}$ Department of Physics, Rensselaer Polytechnic Institute, Troy, NY 12180-3590, USA \\ d Department of Chemistry, University of Oslo, PO Box 1033, Blindern, N-0315 Oslo, Norway

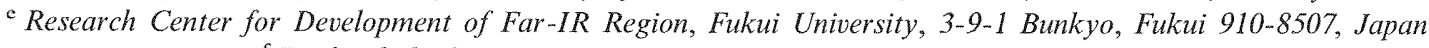 \\ ${ }^{f}$ I. Physikalisches Institut, Universität zu Köln, D50937 Köln, Germany \\ ' Onsala Space Observatory, Chalmers University of Technology, S-43992 Onsala, Sweden \\ ${ }^{\text {h }}$ National Astronomical Observatory of Japan, 2-21-1, Ohsawa, Mitaka, Tokyo, 181, Japan
}

\begin{abstract}
Rotational spectroscopy at millimeter wavelengths is a powerful means of investigating the chemistry of dense interstellar clouds. These regions can exhibit an interesting complement of gas phase molecules, including relatively complex organics. Here we report the tentative first astronomical detection of aziridine (ethylenimine), the possible detection of propenal (acrolein), and upper limits on the abundances of cyclopropenone, furan, hydroxyethanal (glycolaldehyde), thiohydroxylamine $\left(\mathrm{NH}_{2} \mathrm{SH}\right)$, and ethenol (vinyl alcohol) in various interstellar clouds.
\end{abstract}

Keywords: Interstellar molecules; Rotational spectra; Propenal; Aziridine; Cyclopropenone; Furan; Hydroxyethanal

\section{Introduction}

Over the last three decades astronomers have discovered that the denser clouds in the interstellar medium (ISM) have a complex chemistry involving both particulate matter (interstellar grains) and a gas phase in which more than 100 molecular species have been securely identified [1-3]. The latter include molecules with up to at least 13 atoms and molecular weights up to 147 (Table 1). In addition, there is strong evidence for even heavier aromatic molecules, although specific assignments have been difficult to achieve [4].

This interstellar chemistry is scientifically important, both in its own right as it pertains to the largest objects in the universe whose composition 
is subject to chemical bonding; and in its application to astrophysical problems such as star formation, where cooling of clouds by trace molecular constituents and the coupling to magnetic fields through the abundance of ions are critically important [5]. Moreover, the low temperatures (often $\approx 10 \mathrm{~K}$ ) and densities $\left(\geq 10^{4}\right.$ molecules $\mathrm{cm}^{-3}$ in 'dense' regions) make these clouds interesting laboratories where the spectra and structure of a number of molecular species have been studied before this was possible in the laboratory (e.g. [6-8]). Finally, since interstellar organic molecules may well be incorporated into comets and hence brought to the early Earth, it is at least conceivable that such exogenous ma- terial may have played some role in the origin of life $[15,53]$.

Although much is known about the chemistry of dense interstellar clouds, much also remains uncertain, as a result of the variety of heterogeneous processes which may be important, including the effects of radiation fields and cosmic rays. Absolute abundances are difficult to determine as a function of physical conditions; such conditions vary significantly among and within different environments; reaction rates and branching ratios in the gas phase may not be known at relevant temperatures; the nature of grain surfaces and hence processes on and in grains are poorly constrained (although spectra

Table 1

Gas phase interstellar and circumstellar molecules

\begin{tabular}{|c|c|c|c|c|c|c|c|c|}
\hline 2 Atoms & 3 Atoms & 4 Atoms & 5 Atoms & 6 Atoms & 7 Atoms & 8 Atoms & 9 Atoms & $\geq 10$ Atoms \\
\hline $\mathrm{H}_{2}$ & $\mathrm{C}_{2} \mathrm{H}$ & $\mathrm{C}_{2} \mathrm{H}_{2}$ & $\mathrm{C}_{4} \mathrm{H}$ & $\mathrm{C}_{2} \mathrm{H}_{4}{ }^{\mathrm{a}}$ & $\mathrm{C}_{6} \mathrm{H}$ & $\mathrm{CH}_{3} \mathrm{COOH}$ & $\mathrm{CH}_{3} \mathrm{C}_{4} \mathrm{H}$ & $\mathrm{CH}_{3} \mathrm{C}_{4} \mathrm{CN}^{\mathrm{b}}$ \\
\hline $\mathrm{C}_{2}$ & $\mathrm{CH}_{2}$ & 1. $\mathrm{C}_{3} \overline{\mathrm{H}}$ & $\mathrm{C}_{3} \mathrm{H}_{2}$ & $\mathrm{H}_{2} \mathrm{CCCC}$ & $\mathrm{HC}_{5} \mathrm{~N}$ & $\mathrm{HCOOCH}_{3}$ & $\mathrm{CH}_{3} \mathrm{OCH}_{3}$ & $\mathrm{CH}_{3} \mathrm{COCH}_{3}$ \\
\hline $\mathrm{CH}$ & $\mathrm{HCN}$ & $\mathrm{c}-\mathrm{C}_{3} \mathrm{H}^{\mathrm{c}}$ & $\mathrm{H}_{2} \mathrm{CCC}$ & $\mathrm{CH}_{3} \mathrm{OH}$ & $\mathrm{CH}_{2} \mathrm{CHCN}$ & $\mathrm{C}_{7} \mathrm{H}^{\mathrm{a}}$ & $\mathrm{CH}_{3} \mathrm{CH}_{2} \mathrm{CN}$ & $\mathrm{HC}_{9} \mathrm{~N}$ \\
\hline $\mathrm{CH}^{+}$ & $\mathrm{HNC}$ & $\mathrm{NH}_{3}$ & $\mathrm{HCOOH}$ & $\mathrm{CH}_{3} \mathrm{CN}$ & $\mathrm{CH}_{3} \mathrm{C}_{2} \mathrm{H}$ & $\mathrm{H}_{2} \mathrm{C}_{6}$ & $\mathrm{CH}_{3} \mathrm{CH}_{2} \mathrm{OH}$ & $\mathrm{HC}_{11} \mathrm{~N}$ \\
\hline $\mathrm{CN}$ & $\mathrm{HCO}$ & HNCO & $\mathrm{CH}_{2} \mathrm{CO}$ & $\mathrm{CH}_{3} \mathrm{NC}$ & $\mathrm{CH}_{3} \mathrm{CHO}$ & $\mathrm{HC}_{6} \mathrm{H}^{\mathrm{a}}$ & $\mathrm{HC}_{7} \mathrm{~N}$ & $\left(\mathrm{C}_{2} \mathrm{H}_{5}\right)_{2} \mathrm{O}^{\mathrm{b}}$ \\
\hline $\mathrm{CO}$ & $\mathrm{HCO}^{+}$ & $\mathrm{HOCO}^{+}$ & $\mathrm{HC}_{3} \mathrm{~N}$ & $\mathrm{CH}_{3} \mathrm{SH}$ & $\mathrm{CH}_{3} \mathrm{NH}_{2}$ & $\mathrm{CH}_{3} \mathrm{C}_{3} \mathrm{~N}$ & $\mathrm{C}_{8} \mathrm{H}$ & \\
\hline $\mathrm{CS}$ & $\mathrm{HOC}^{+}$ & $\mathrm{HCNH}^{+}$ & $\mathrm{CH}_{2} \mathrm{CN}$ & $\mathrm{NH}_{2} \mathrm{CHO}$ & $\mathrm{c}-\mathrm{CH}_{2} \mathrm{OCH}_{2}^{\mathrm{c}}$ & & & \\
\hline $\mathrm{OH}$ & $\mathrm{N}_{2} \mathrm{H}^{+}$ & HNCS & $\mathrm{NH}_{2} \mathrm{CN}$ & $\mathrm{HC}_{3} \mathrm{HO}$ & & & & \\
\hline $\mathrm{NH}$ & $\mathrm{NH}_{2}$ & $\mathrm{C}_{3} \mathrm{~N}$ & $\mathrm{CH}_{2} \mathrm{NH}$ & $\mathrm{C}_{5} \mathrm{H}$ & & & & \\
\hline NO & $\mathrm{H}_{2} \mathrm{O}$ & $\mathrm{C}_{3} \mathrm{O}$ & $\mathrm{CH}_{4}$ & $\mathrm{HC}_{3} \mathrm{NH}^{+}$ & & & & \\
\hline NS & $\mathrm{HCS}^{+}$ & $\mathrm{H}_{2} \mathrm{CS}$ & $\mathrm{SiH}_{4}{ }^{\mathrm{a}}$ & $\mathrm{C}_{5} \mathrm{~N}$ & & & & \\
\hline $\mathrm{SiC}^{\mathrm{a}}$ & $\mathrm{H}_{2} \mathrm{~S}$ & $\mathrm{C}_{3} \mathrm{~S}$ & $\mathrm{C}_{4} \mathrm{Si}^{\mathrm{a}}$ & $\mathrm{HC}_{4} \mathrm{H}^{\mathrm{a}}$ & & & & \\
\hline $\mathrm{SiO}$ & OCS & $\mathrm{HCCN}$ & $\mathrm{C}_{5}^{\mathrm{a}}$ & & & & & \\
\hline SiS & $\mathrm{N}_{2} \mathrm{O}$ & $\mathrm{H}_{3} \mathrm{O}^{+}$ & HCCNC & & & & & \\
\hline $\operatorname{SiN}^{a}$ & $\mathrm{SO}_{2}$ & $\mathrm{H}_{2} \mathrm{CN}$ & HNCCC & & & & & \\
\hline SO & $\mathrm{SiC}_{2}$ & $\mathrm{H}_{2} \mathrm{CO}$ & $\mathrm{H}_{2} \mathrm{COH}^{+}$ & & & & & \\
\hline $\mathrm{HCl}$ & $\mathrm{C}_{2} \mathrm{~S}$ & $\mathrm{C}-\mathrm{SiC}_{3}{ }^{\mathrm{c}}$ & & & & & & \\
\hline $\mathrm{CP}^{\mathrm{a}}$ & $\mathrm{C}_{2} \mathrm{O}$ & $\mathrm{CH}_{3}$ & & & & & & \\
\hline $\mathrm{SO}^{+}$ & $\mathrm{C}_{3}$ & & & & & & & \\
\hline $\mathrm{NaCl}^{\mathrm{a}}$ & $\mathrm{MgNC}^{\mathrm{a}}$ & & & & & & & \\
\hline $\mathrm{AlCl}^{\mathrm{a}}$ & $\mathrm{MgCN}^{\mathrm{a}}$ & & & & & & & \\
\hline $\mathrm{KCl}^{\mathrm{a}}$ & $\mathrm{NaCN}^{\mathrm{a}}$ & & & & & & & \\
\hline $\mathrm{AlF}^{\mathrm{a}}$ & HNO & & & & & & & \\
\hline $\mathrm{PN}$ & $\mathrm{H}_{3}^{+}$ & & & & & & & \\
\hline \multicolumn{9}{|l|}{$\mathrm{CO}^{+}$} \\
\hline $\mathrm{SiH}^{\mathrm{b}}$ & & & & & & & & \\
\hline $\mathrm{HF}^{\mathrm{b}}$ & & & & & & & & \\
\hline
\end{tabular}

\footnotetext{
${ }^{a}$ Detected only in stellar envelopes.

b Tentative detection.

${ }^{\mathrm{c}} \mathrm{C}$-, cyclic structure. For references, see $[50,61,62]$.
} 
Table 2

Source information ${ }^{\mathrm{a}}$

\begin{tabular}{|c|c|c|c|c|c|c|}
\hline Source & $\alpha(1950.0)$ & $\delta(1950.0)$ & $V_{\mathrm{LSR}}\left[\mathrm{km} \mathrm{s}^{-1}\right]^{\mathrm{b}}$ & $\mathrm{N}\left(\mathrm{H}_{2}\right)\left[\mathrm{cm}^{-2}\right]^{\mathrm{c}}$ & $\Theta_{\mathrm{mb}}[\operatorname{arcsec}]^{\mathrm{d}}$ & Reference/comments \\
\hline TMC-1(CP) & $04^{\mathrm{h}} 38^{\mathrm{m}} 38.6^{\mathrm{s}}$ & $+25^{\circ} 35^{\prime} 45.0^{\prime \prime}$ & +5.8 & $2.0(22)$ & 50 & [23] from $\mathrm{C}^{18} \mathrm{O}$ \\
\hline Orion KL & $05^{\mathrm{h}} 32^{\mathrm{m}} 47.0^{\mathrm{s}}$ & $-05^{\circ} 24^{\prime} 23.0^{\prime \prime}$ & +9.0 & $1.0(23)$ & 50 & [28] from $\mathrm{C}^{18} \mathrm{O}$ \\
\hline Orion $3 \mathrm{~N}$ & $05^{\mathrm{h}} 32^{\mathrm{m}} 51.0^{\mathrm{s}}$ & $-05^{\circ} 20^{\prime} 50.0^{\prime \prime}$ & +9.0 & $5.0(22)$ & 50 & [28] from $\mathrm{C}^{18} \mathrm{O}$ \\
\hline $\mathrm{G} 327.3-0.6$ & $15^{\mathrm{h}} 49^{\mathrm{m}} 15.6^{\mathrm{s}}$ & $-54^{\circ} 28^{\circ} 07.0^{\prime \prime}$ & -45.0 & $3.0(23)$ & 45 & [51] from $\mathrm{C}^{18} \mathrm{O}$ \\
\hline $\mathrm{L} 134 \mathrm{~N}(\mathrm{C})$ & $15^{\mathrm{h}} 51^{\mathrm{m}} 32.6^{\mathrm{s}}$ & $-02^{\circ} 43^{\prime} 31.0^{\prime \prime}$ & +2.5 & $1.5(22)$ & 50 & [24] from $\mathrm{C}^{18} \mathrm{O}$ \\
\hline IRS 16293 & $16^{\mathrm{h}} 29^{\mathrm{m}} 20.9^{\mathrm{s}}$ & $-24^{\circ} 22^{\prime} 13.0^{\prime \prime}$ & +4.0 & $2.0(23)$ & 20 & [25] from $\mathrm{C}^{17} \mathrm{O}$ \\
\hline NGC 6334F & $17^{\mathrm{h}} 17^{\mathrm{m}} 32.3^{\mathrm{s}}$ & $-35^{\circ} 44^{\prime} 02.5^{\prime \prime}$ & -7.0 & $2.0(23)$ & 45 & [21] from $\mathrm{C}^{17} \mathrm{O}$ \\
\hline $\operatorname{SgrB} 2 \mathrm{~N}$ & $17^{\mathrm{h}} 44^{\mathrm{m}} 10.1^{\mathrm{s}}$ & $-28^{\circ} 21^{\prime} 17.0^{\prime \prime}$ & +68.0 & $3.0(24)$ & 23 & [18] from $\mathrm{C}^{17} \mathrm{O}$ \\
\hline $\mathrm{G} 10.47+0.03$ & $18^{\mathrm{h}} 05^{\mathrm{m}} 40.3^{\mathrm{s}}$ & $-19^{\circ} 52^{\prime} 21.0^{\prime \prime}$ & +68.0 & $1.0(23)$ & 45 & [21] from $\mathrm{C}^{17} \mathrm{O}$ \\
\hline W33A & $18^{\mathrm{h}} 14^{\mathrm{m}} 26.3^{\mathrm{s}}$ & $-17^{\circ} 52^{\prime} 01.0^{\prime \prime}$ & +32.0 & $6.2(23)$ & 14 & [52] from $\mathrm{C}^{17} \mathrm{O}$ \\
\hline $\mathrm{G} 31.41+0.31$ & $18^{\mathrm{h}} 44^{\mathrm{m}} 59.2^{\mathrm{s}}$ & $-01^{\circ} 16^{\prime} 07.0^{\prime \prime}$ & +97.0 & $2.0(23)$ & 45 & [21] from $\mathrm{C}^{17} \mathrm{O}$ \\
\hline $\mathrm{G} 34.3+0.2$ & $18^{\mathrm{h}} 50^{\mathrm{m}} 46.2^{\mathrm{s}}$ & $+01^{\circ} 11^{\prime} 13.0^{\prime \prime}$ & +58.0 & $3.0(23)$ & 45 & [21] from $\mathrm{C}^{17} \mathrm{O}$ \\
\hline
\end{tabular}

Note: notation a(b) represents a $\times 10^{b}$.

${ }^{b} V_{\text {LSR }}$, is the radial velocity of the source with respect to the local standard of rest (see text).

${ }^{\mathrm{c}} \mathrm{N}\left(\mathrm{H}_{2}\right)$, is the column density of molecular hydrogen along the line of sight as estimated from the CO isotopomer indicated in the last column.

${ }^{d} \Theta_{\mathrm{mb}}$, is the antenna main beam size (full width half power).

show that the grains contain both silicates and poorly characterized organic material $[5,74]$ ); and the interchange of material between solid and gas phases is not well understood $[9,10]$. Thus, the additional constraints on models supplied by the identification of new molecular species and the determination of their abundance remains very important.

The increased sensitivity of infrared detectors and the necessity of such measurements for nonpolar species and for solid state features are increasing the importance of infrared observations of vibrational spectra for interstellar chemistry (e.g. $[11,12])$. Nonetheless, the great bulk of the relevant data come from heterodyne observations of rotational spectra at millimeter and submillimeter wavelengths. Rotational spectroscopy is thus critical to this field, and key data are often lacking, particularly for 'unstable' species such as radicals and positive ions, or even for well known molecules in high rotational levels, in low-lying vibrational states, and for rarer isotopomers (cf. the recent important work on species such as methanol and methyl formate (methyl methanate; e.g. $[13,14]$ ).

Here we report on searches for several previously undetected molecules in a number of interstellar sources. These particular searches were motivated by the identification of related species in interstellar clouds or, in one case, in a comet (the chemistry of cometary comae is remarkably similar to that in the ISM, either because of the presence of preserved interstellar material or because of similar conditions in the ISM to those in the region of cometary formation in the solar nebula [15]). We have taken advantage of the relatively large body of data which we accumulated in several searches targeted for certain molecules, to seek for other species with transitions in the frequency ranges encompassed by the data. Our observed frequency bands fall within the general ranges $18-23,85-115,130-$ 170 , and $210-260 \mathrm{GHz}$ (wavelengths of about $17-13,3.5-2.6,2.3-1.8$, and $1.4-1.2 \mathrm{~mm}$, respectively).

Observations were made at the $15 \mathrm{~m}$ diameter Swedish-ESO Submillimeter Telescope (SEST) in Chile, the US National Radio Astronomy Observatory's $12 \mathrm{~m}$ telescope in Arizona, and the NASA DSN $70 \mathrm{~m}$ telescope. Our observed sources (Table 2) are primarily examples of the regions called hot cores, which are present around very young, massive stars or protostars (e.g. $[2,16,18])$. These hot cores include Orion $\mathrm{KL}$ (the closest such region to the Sun, and 
consequently known to have a complex physical and chemical structure; cf. [19]), G327.3-0.6 $[20,21], \quad N G C$ 6334F [21], SgrB2 $N$ (in the Galactic Center region [18]), G10.47+0.03 [22], $\mathrm{G} 31.41+0.31[21,22]$ and $\mathrm{G} 34.3+0.2[17,21]$. In addition, we observed on some occasions the cold, dark clouds TMC-1(CP) and L134N(C), regions where solar type stars may eventually form [23,24]; IRS 16293, a cloud where a solar type star(s) has indeed formed $[25,26]$; the line of sight toward a very deeply embedded massive star in a giant molecular cloud, W33A (e.g. [27]); and the quiescent gas near a region of massive star formation, Orion 3 N [28]. Because of the heterodyne techniques available at these frequencies, very high spectral resolution was obtained, typically $>100000$ and often $>$ 500000 . We note that comparing the observed spectrum to one obtained in the laboratory requires a Doppler correction for the relative motion of the source region relative to the telescope. This velocity is conveniently separated into two parts, the motion of the observer with respect to the Local Standard of Rest (LSR; the coordinate system defined by a hypothetical star at the location of the Sun, but moving in a closed orbit in the plane of our Milky Way Galaxy [64]), and the velocity of the source (VLSR) with respect to this coordinate system. The latter is determined from the source's spectrum, since the pattern of expected strong lines is easily recognized. The detailed observing techniques are described elsewhere [21,29].

A sample spectrum of the hot core G327.30.6 is given in Fig. 1. As is typical of hot core regions, emission lines from a variety of organic species are seen, with typical linewidths (from Doppler broadening by mass motions within the cloud) of order $5 \mathrm{~km} \mathrm{~s}^{-1}$, or $2.5 \mathrm{MHz}$ at 150 $\mathrm{GHz}$. In addition, there are a number of unassigned features. Although some of the latter may ultimately be assigned to new interstellar molecules, our experience suggests that many (if not most) of them may arise from as yet uncataloged transitions of known interstellar species, including high-J lines, transitions within low-lying vibrational states, and transitions of rarer isotopomers (cf. [30]).

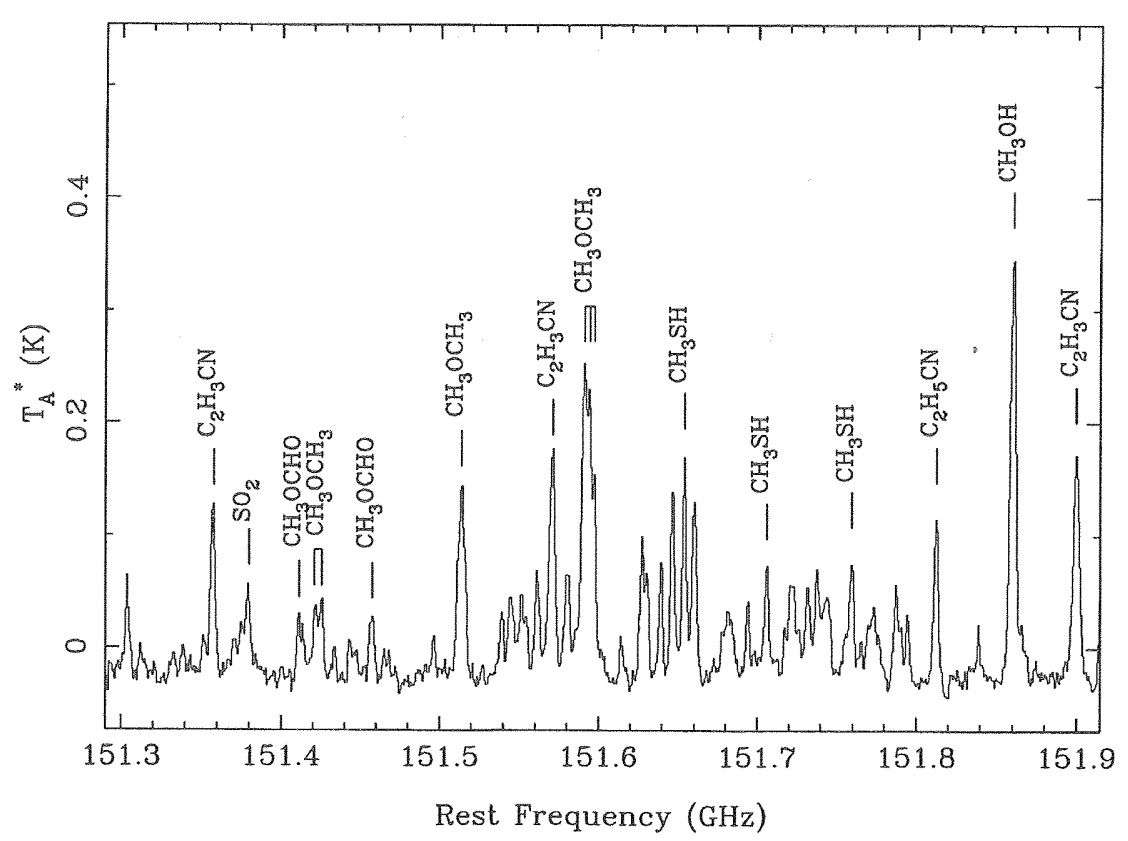

Fig. 1. A sample spectrum in the $2 \mathrm{~mm}$ wavelength region for the southern hemisphere hot core source G327.3-0.6. Intensity given as antenna temperature $T_{u}^{*}$ (see text). Emission lines are rotational transitions of the molecular species indicated. Unlabeled lines are either unassigned (see text) or have more than one possible assignment. 


\section{Molecular species sought}

We give our results consecutively for each molecular species. Table 3 lists the frequencies, energies above the ground state, and Einstein A-coefficients for the transitions observed for each species except aziridine, for which the transitions are given in Table 4. Because traditionally radio astronomers worked at frequencies $v$ for which the Rayleigh-Jeans approximation was valid $(h v \ll k T)$, it is usual to express intensity $(l)$ in terms of temperature units via

$I(v)=\left(2 h v^{3} / c^{2}\right)[\exp (h v / k T)-1]^{-1} \approx 2 k v^{2} T / c^{2}$,

where the 'brightness temperature' $T$ is the temperature of a hypothetical blackbody filling the beam of a perfect antenna and producing the measured monochromatic flux. Since a real antenna is not perfect and various calibration schemes are used, the observed signal defines an 'antenna temperature' $T_{\mathrm{a}}^{*}$ (e.g. Fig. 1) which is related to the brightness temperature by an efficiency factor. A particular choice of efficiency factor defines the 'main beam antenna temperature' $T_{\mathrm{mb}}$ (Tables 4-6, Figs. 2-5) [9,31].

Table 4 and Table 5 list for aziridine and propenal, respectively, the detected emission lines or the upper limits in each observed source region in units of milliKelvin. Table 6 lists for thiohydroxylamine the upper limits only on signal strength in each observed source region. The upper limits on line intensity for the other species which we have sought are comparable to those for thiohydroxylamine and are not tabulated; instead we give below limits on the derived column densities and abundances. Of particular interest, we report the tentative first astronomical detection of aziridine and a possible first astronomical detection of propenal.

\subsection{Aziridine (ethylenimine, $c-\mathrm{C}_{2} \mathrm{H}_{4} \mathrm{NH}$ )}

Cyclic molecules play a fundamental role in biochemistry. In the diffuse interstellar medium there is strong evidence for the presence of polycyclic aromatic hydrocarbons (PAHs), but specific molecular species have not been identified [4]. In dense interstellar clouds, cyclic species have been hard to find; until recently only the 3-carbon rings $\mathrm{C}_{3} \mathrm{H}$ and $\mathrm{C}_{3} \mathrm{H}_{2}$ had been identified, although two small silicon-containing rings are known in the envelopes of evolved, carbon-rich stars (Table 1). The recent identification of oxirane (ethylene oxide, $\mathrm{c}-\mathrm{C}_{2} \mathrm{H}_{4} \mathrm{O}$ ) in the ISM [21,29] made it natural to investigate the possible presence of the related species aziridine, in which the oxygen is replaced by an NH group. Fortunately, the rotational spectrum at relevant wavelengths has recently been measured $[33,63]$. Although a targeted search for aziridine was not carried out, a number of its transition frequencies were covered in our searches for other molecular species. The predicted relative intensity of these lines of course depends on the assumed rotational temperature. One of the lines which we would expect to be among the strongest at temperatures in the range $30-100 \mathrm{~K}$, which is typically what we would expect in hot molecular cloud cores, is the $9_{09^{-}}$ $8_{18} / 9_{19}-8_{08}$ doublet at $249419.6 \mathrm{MHz}$. This line is unfortunately not observable, being less than 0.4 $\mathrm{MHz}$ from the 15(3)-15(2) A-t line of methanol, which is a very prominent emission feature in all hot cores.

In our data there are two features that may be attributed to aziridine (Table 4). The first is the $5_{50}-4_{41}$ line at $226233.4 \mathrm{MHz}$, where, to the best of our knowledge, no other known interstellar species have transitions. There is a clear emission line here in the spectra of the hot cores G327.3, G10.47, and Sgr B2(N), and a weak line in G34.3 (Fig. 2). The second feature is the $2_{11}-1_{01}$ transition at $86312.7 \mathrm{MHz}$, where a line is detected in G327.3, G10.47, and possibly in G31.41 (Fig. 3). The significance of these detections will be discussed below.

\subsection{Propenal (acrolein, $\mathrm{CH}_{2} \mathrm{CHCHO}$ )}

The presence in a variety of interstellar clouds of both $\mathrm{CH}_{2} \mathrm{CHCN}$ and $\mathrm{CH}_{3} \mathrm{CHO}$ (e.g. $[21,30]$ ) suggests that propenal might also be present. Note that ethene $\left(\mathrm{H}_{2} \mathrm{CCH}_{2}\right)$ has been detected in stellar envelopes through its vibrational spectrum in absorption [61], but its non-polar nature precludes detection of rotational lines in cold interstellar clouds. The trans-form of propenal is more 
Table 3

Molecular transition data

\begin{tabular}{|c|c|c|c|c|}
\hline Rest frequency [MHz] & Transition $\left[J_{K-1, K+1}\right]$ & $E_{\mathrm{u}}[\mathrm{K}]^{\mathrm{a}}$ & $A_{\mathrm{ul}}^{\mathrm{b}}$ & Telescope \\
\hline \multicolumn{3}{|l|}{$\mathrm{CH}_{2} \mathrm{CHOH}$ :ethenol } & \multicolumn{2}{|l|}{$\left[10^{-5} s^{-1}\right]$} \\
\hline 77726.6 & $4_{0,4}-3_{0,3}$ & 9 & 0.092 & NRAO \\
\hline 84401.7 & $8_{1,7}-8_{0,8}$ & 37 & 0.167 & SEST \\
\hline 86557.6 & $2_{1,2}-1_{0,1}$ & 5 & 0.074 & NRAO \\
\hline 101449.2 & $5_{1,4}-4_{1,3}$ & 17 & 0.201 & SEST \\
\hline 222996.9 & $4_{2.3}-3,3$ & 19 & 1.758 & NRAO \\
\hline 238774.0 & $12_{1,12}-11_{0,11}$ & 72 & 3.620 & NRAO \\
\hline 240593.6 & $12_{1.11}-11_{1,01}$ & 78 & 2.925 & SEST \\
\hline 240786.7 & $13_{1.13}-12_{1.12}$ & 84 & 2.948 & SEST \\
\hline 249262.5 & $3_{3,0}-3_{2.1}$ & 27 & 1.497 & SEST \\
\hline 249560.1 & $4,-4_{2,3}$ & 31 & 2.112 & SEST \\
\hline 249773.7 & $5_{3,3}-5_{2,4}$ & 36 & 2.433 & SEST \\
\hline 250143.9 & $6_{3,4}-6_{2,5}$ & 41 & 2.632 & SEST \\
\hline \multicolumn{3}{|l|}{$\mathrm{c}-\mathrm{C}_{3} \mathrm{H}_{2} \mathrm{O}$ :cyclopropenone } & \multicolumn{2}{|l|}{$\left[10^{-5} \mathrm{~s}^{-1}\right]$} \\
\hline 23105.6 & $5_{1,4}-5_{1,5}$ & 12 & 0.009 & DSN \\
\hline 74052.8 & $5_{1,4}^{-4} 1,3$ & 12 & 3.971 & NRAO \\
\hline 82283.2 & $6_{0,6}-5_{0.5}$ & 14 & 5.727 & NRAO \\
\hline 103069.9 & $7_{1,6}-6_{1,5}$ & 21 & 10.199 & NRAO \\
\hline 105476.5 & $8_{1,8}-7_{1,7}$ & 24 & 12.170 & NRAO \\
\hline 107805.0 & $8_{0,8}-7_{0,7}$ & 24 & 13.101 & SEST \\
\hline \multicolumn{3}{|l|}{ c- $\mathrm{C}_{4} \mathrm{H}_{4} \mathrm{O}$ :furan } & \multicolumn{2}{|l|}{$\left[10^{-6} s^{-1}\right]$} \\
\hline 23402.5 & $4_{3,2}-4_{1,3}$ & 8 & 0.012 & DSN \\
\hline 23453.1 & $2_{0,2}-1_{0,1}$ & 2 & 0.023 & DSN \\
\hline 70074.7 & $6_{1,5}-5_{1,4}$ & 13 & 0.697 & NRAO \\
\hline 88748.7 & $9_{0,9}-8_{0.8}$ & 22 & 1.786 & SEST \\
\hline 107431.0 & $11_{0,11}-10_{0,10}$ & 32 & 3.232 & SEST \\
\hline 210175.6 & $22_{0,22}-21_{0.21}$ & 118 & 25.31 & NRAO \\
\hline \multicolumn{3}{|l|}{$\mathrm{CH}_{2} \mathrm{OHCHO}$ :hydroxyethanal } & \multicolumn{2}{|l|}{$\left[10^{-7} \mathrm{~s}^{-1}\right]$} \\
\hline 17981.1 & $3_{1,2}-3_{0.3}$ & 4 & 2.132 & DSN \\
\hline 22142.9 & $4_{1,3}-4_{0,4}$ & 6 & 3.453 & DSN \\
\hline 22252.8 & $9_{3,6}-8_{4,5}$ & 30 & 0.436 & DSN \\
\hline 23415.7 & $1_{1,1}-0_{0,0}$ & 1 & 3.712 & DSN \\
\hline 23415.9 & $3_{0,3}-2_{1,2}$ & 2 & 2.080 & DSN \\
\hline \multicolumn{3}{|l|}{$\mathrm{CH}_{2} \mathrm{CHCHO}$ :propenal } & \multicolumn{2}{|l|}{$\left[10^{-5} s^{-1}\right]$} \\
\hline 88523.3 & $10_{0,10^{-9}}-9$ & 23 & 2.753 & SEST \\
\hline 88540.6 & $32_{5.27}-33_{4.30}$ & 277 & 0.022 & SEST \\
\hline 89043.5 & $10_{6,4}-96,3$ & 98 & 1.794 & SEST \\
\hline 89082.2 & $10_{3,8}-9_{3,7}$ & 42 & 2.554 & SEST \\
\hline 89093.2 & $10_{3,7}-93,6$ & 42 & 2.555 & SEST \\
\hline 94414.6 & $21_{1,20}-21_{1.21}$ & 102 & 0.016 & NRAO \\
\hline 97263.1 & $11_{0.11}-10_{0.10}$ & 28 & 3.669 & NRAO \\
\hline 107404.2 & $21_{1,20}-21_{0,21}$ & 102 & 0.119 & SEST \\
\hline 107528.8 & $12_{2,10^{-}}-11_{2,9}$ & 42 & 4.845 & SEST \\
\hline \multicolumn{3}{|l|}{ NH2SH:thiohydroxylamine } & \multicolumn{2}{|l|}{$\left[10^{-6} \mathrm{~s}^{-1}\right]$} \\
\hline 84243.6 & $3_{1,3}-2_{1,2}$ & 14 & 2.349 & SEST \\
\hline
\end{tabular}

${ }^{a} E_{u}$ is the energy of the upper level above the ground state for the transition.

${ }^{\mathrm{b}} A_{\mathrm{ul}}$ is the rate of spontaneous emission from the upper to lower level, also called the Einstein $A$-coefficient. 
stable than the cis-form, which lies about 700 $\mathrm{cm}^{-1}$ higher in energy. The rotational spectrum of trans-propenal is known from laboratory measurements [32].

Although we did not specifically target propenal in any of our searches, six unassigned emission lines which we observed corresponded very well in frequency to transitions of trans propenal (Table 5 and Figs. 4 and 5). The significance of these results is discussed in Section 3 below.

\subsection{Cyclopropenone $\left(c-\mathrm{C}_{3} \mathrm{H}_{2} \mathrm{O}\right)$}

Cyclopropenylidene $\left(\mathrm{c}-\mathrm{C}_{3} \mathrm{H}_{2}\right)$ is ubiquitous and relatively abundant in a variety of interstellar and circumstellar environments, and possibly in comets as well [37-39]. The linear carbon chains $\mathrm{C}_{3} \mathrm{O}$ and $\mathrm{C}_{2} \mathrm{O}$ are less common, but are found $[40,41]$. It is therefore natural to search for interstellar cyclopropenone $\left(\mathrm{c}-\mathrm{C}_{3} \mathrm{H}_{2} \mathrm{O}\right)$, in which the unbonded electrons of $\mathrm{c}-\mathrm{C}_{3} \mathrm{H}_{2}$ are shared with an oxygen atom. We used the transition frequencies measured by Guillemin et al. [42]. Several transitions in the range from 23 to $108 \mathrm{GHz}$ were sought (Table 3 ), but only upper limits were obtained. The procedure for obtaining upper limits on the column density toward each observed source (Table 7) is described in Section 3.3 below.

\subsection{Ethenol (vinyl alcohol, $\mathrm{CH}_{2} \mathrm{CHOH}$ )}

Ethenol is an isomer of two known interstellar molecules, oxirane $\left(\mathrm{c}-\mathrm{C}_{2} \mathrm{H}_{4} \mathrm{O}\right)$ and ethanal (acetaldehyde, $\mathrm{CH}_{3} \mathrm{CHO}$ ). It has a heat of formation intermediate between those two species and hence might be thought to be intermediate in stability. Although other structural isomers are found in the ISM (e.g. $\mathrm{HCN} / \mathrm{HNC}, \mathrm{CH}_{3} \mathrm{CN} / \mathrm{CH}_{3} \mathrm{NC}$, cyclic- $\mathrm{C}_{3} \mathrm{H}_{2} /$ linear- $\left.\mathrm{H}_{2} \mathrm{C}_{3}, \quad \mathrm{CH}_{2} \mathrm{CH}_{2} \mathrm{OH} /\left(\mathrm{CH}_{3}\right)_{2} \mathrm{O}\right)$, the detection of ethenol would provide the first triplet of such isomers. Laboratory data obtained by Saito [43] have been augmented by his more recent, higher frequency measurements for the present study. A number of transitions in the 3 $\mathrm{mm}$ and $1 \mathrm{~mm}$ bands were sought in several sources, but no lines were detected. The corresponding upper limits on column density are given in Table 7.

\subsection{Furan $\left(\mathrm{C}_{4} \mathrm{H}_{4} \mathrm{O}\right)$}

As noted above, the only cyclic species unambiguously identified to date in interstellar clouds are the 3-membered rings $\mathrm{C}_{3} \mathrm{H}_{2}, \mathrm{C}_{3} \mathrm{H}$, and $\mathrm{c}$ $\mathrm{C}_{2} \mathrm{H}_{4} \mathrm{O}$. As there is substantial evidence for polycyclic aromatic species from infrared spectral features that can be assigned to functional groups, however, it is natural to seek larger ring molecules in dense clouds. Searches for, e.g. furan, pyrrole

Table 4

Aziridine Observations

\begin{tabular}{|c|c|c|c|c|c|c|c|c|c|}
\hline Transition & $\begin{array}{l}\text { Frequency } \\
(\mathrm{MHz})\end{array}$ & $\begin{array}{l}E_{\mathrm{u}} \\
(\mathrm{K})^{\mathrm{a}}\end{array}$ & $\begin{array}{l}A_{\mathrm{ul}} \\
\left(10^{-5} \mathrm{~s}^{-1}\right)^{\mathrm{a}}\end{array}$ & $\begin{array}{l}\mathrm{G} 327.3 \\
T_{\mathrm{mb}}(\mathrm{mK})^{\mathrm{a}}\end{array}$ & $\begin{array}{l}\text { NGC633 } \\
T_{\mathrm{mb}}(\mathrm{mK})^{\mathrm{a}}\end{array}$ & $\begin{array}{l}\mathrm{G} 10.47 \\
T_{\mathrm{mb}}(\mathrm{mK})^{\mathrm{a}}\end{array}$ & $\begin{array}{l}\mathrm{G} 31.41 \\
T_{\mathrm{mb}}(\mathrm{mK})^{\mathrm{a}}\end{array}$ & $\begin{array}{l}\mathrm{G} 34.3 \\
T_{\mathrm{mb}}(\mathrm{mK})^{\mathrm{a}}\end{array}$ & $\begin{array}{l}\text { SgrB2 } \\
T_{\mathrm{m}}(\mathrm{mK})^{\mathrm{a}}\end{array}$ \\
\hline $2_{11^{-1}} 1_{01}$ & 86312.7 & 6 & 0.413 & 51 & $<10$ & 32 & 17 & & \\
\hline $3_{13}-2_{02}$ & 88964.3 & 9 & 0.269 & $<4$ & $<4$ & & & & \\
\hline $3_{03}-2_{12}$ & 88739.7 & 9 & 0.269 & $<4$ & $<4$ & & & & \\
\hline $8_{35}-8_{26}$ & 93472.9 & 65 & 0.147 & $<9$ & & & & & \\
\hline $8_{45}-8_{36}$ & 93494.1 & 65 & 0.147 & $<9$ & & & & & \\
\hline $5_{05}-4_{14}$ & 142374.3 & 21 & 1.28 & b & b & b & $\mathrm{b}$ & & \\
\hline $5_{15}-4_{04}$ & 142375.6 & 21 & 1.28 & $\mathrm{~b}$ & b & b & b & & \\
\hline $5_{50}-4_{41}$ & 226233.4 & 32 & 3.99 & 90 & $<22$ & 79 & $<20$ & 27 & 290 \\
\hline
\end{tabular}

\footnotetext{
${ }^{a} E_{\mathrm{u}}$ is energy of the upper level of the transition above the ground state; $A_{\mathrm{ul}}$ is the Einstein A-coefficient; the last 6 columns give the observed main beam antenna temperatures (see text, [31]) or $1 \sigma$ upper limits toward the 6 indicated sources (see Table 2).

${ }^{\mathrm{b}}$ Possible blending with the $12-11$ transition of $\mathrm{OC}^{34} \mathrm{~S}$ makes aziridine upper limit uncertain.
} 
Table 5

Propenal possible detections and upper limits ${ }^{\mathrm{a}}$

\begin{tabular}{|c|c|c|c|c|c|c|c|c|c|}
\hline \multirow[t]{2}{*}{ Source } & \multicolumn{9}{|l|}{$T_{\mathrm{mb}}(\mathrm{mK})$} \\
\hline & $32_{5,27}-33_{4,30}$ & $10_{6.4}-9_{6,3}$ & $10_{3,8}-9_{3,7}$ & $10_{3,7}-9_{3,6}$ & $21_{1,20}-21_{1,21}$ & $21_{1,20}-21_{0,21}$ & $10_{0,10^{-}}-9_{0,9}$ & $11_{0,11}-10_{0,10}$ & $\begin{array}{l}12_{2,10} \\
-11_{2,9}\end{array}$ \\
\hline $\mathrm{G} 327.3-0.6$ & 15.0 & 9.0 & 13.0 & 23.0 & 30.0 & 18.0 & $<3.4$ & $<6.4$ & $<5.0$ \\
\hline NGC $6334 \mathrm{~F}$ & $<3.6$ & $<3.6$ & $<3.6$ & $<3.6$ & $<7.0$ & $<5.0$ & $<3.6$ & $<6.0$ & $<4.5$ \\
\hline SgrB2N & $<9.0$ & 44.0 & 51.0 & 99.0 & $\ldots$ & 59.0 & $<6.5$ & $\ldots$ & $<6.0$ \\
\hline $\mathrm{G} 10.47+0.03$ & $\ldots$ & $\ldots$ & $\ldots$ & $\ldots$ & $<7.0$ & $\ldots$ & $\ldots$ & $<6.5$ & $\ldots$ \\
\hline $\mathrm{G} 31.41+0.31$ & $\ldots$ & $\ldots$ & $\ldots$ & $\ldots$ & 13.0 & $\ldots$ & $\ldots$ & $<6.5$ & $\ldots$ \\
\hline
\end{tabular}

a Note: Entries with $<$ are $1 \sigma \mathrm{rms}$ upper limits.

and imidazole [44-46] had been carried out some years ago, but instrumental sensitivity has improved substantially since that time. Furan has a special significance for prebiotic chemistry, since this ring forms the basis of the simple sugars ribose and deoxyribose, the backbone molecules of RNA and DNA. Molecular constants accurate enough to predict furan transition frequencies for $J<30$ to better than $60 \mathrm{kHz}$ have been measured by Wlodarczak et al. [47]. We sought transitions over a wide range of frequencies and energies above ground (Table 3) in several astronomical sources. Only upper limits were obtained, from which the column density limits in Table 7 were derived.

\subsection{Hydroxyethanal (glycolaldehyde, $\mathrm{HOCH}_{2} \mathrm{CHO}$ )}

Hydroxyethanal is an isomer of both methyl formate (methyl methanate, $\mathrm{HCOOCH}_{3}$ ) and acetic acid (ethanoic acid, $\mathrm{CH}_{3} \mathrm{COOH}$ ). Methyl formate is widespread among regions of massive star formation, with a very large number of detected transitions at millimeter wavelengths (e.g. $[54,17,18])$. Acetic acid, in contrast, has probably been detected in only a single source [55]. Ab initio calculations were carried out for the preferred conformers of acetic acid [67], methyl formate [68] and hydroxyethanal [49] using the correlation-consistent polarized triple-zeta basis set with diffuse functions [69] (AUG-cc-pVTZ) in the Møller-Plesset (MP) second-order perturbation procedure [70] with full geometry optimization. The Gaussian 98 program [71] was employed in these computations.
Interestingly, these very high level MP2/AUG-ccpVTZ calculations predict acetic acid (total energy: $-600511.17 \mathrm{~kJ} \mathrm{~mol}^{-1}$ ) to be about $72 \mathrm{~kJ} \mathrm{~mol}^{-1}$ more stable than methyl formate, showing that the formation of methyl formate is controlled by kinetic factors and not by thermodynamics (as is expected under typical conditions in interstellar clouds). Hydroxyethanal is the highest energy isomer of the 3 , being about $118 \mathrm{~kJ} \mathrm{~mol}^{-1}$ less stable than acetic acid. Although, as noted in Section 2.4, other structural isomeric pairs are found in the ISM, no triplets have been identified. Because of the likelihood of related pathways for production and destruction of such isomers, determination of their relative abundance should place significant constraints on chemical models. Hydroxyethanal is also important as a potential intermediary in the prebiotic syntheses of sugars and sugar phosphates (e.g. [48]).

Our search was carried out exclusively at the NASA DSN $70 \mathrm{~m}$ telescope, at frequencies in the 18-23 GHz range (Table 3), using the transition frequencies given by Marstokk and Møllendal [49], supplemented by more recent laboratory data by one of us (HM). No emission features were detected which corresponded to transitions of hydroxyethanal. The relationship of our limits to a recent reported detection of hydroxyethanal [73] is discussed in Section 4 below.

\subsection{Thiohydroxylamine $\left(\mathrm{NH}_{2} \mathrm{SH}\right)$}

The first cometary molecule containing both nitrogen and sulfur, the NS radical, was recently 
identified in the coma (atmosphere) of comet HaleBopp [34]. It is unclear whether such a radical could be stored in the nuclear ices over the lifetime of the solar system. It seems more likely that it is either the photodissociation product of some larger precursor, or the product of chemistry in the coma [35]. In the former case a logical precursor might be $\mathrm{NH}_{2} \mathrm{SH}$, since such simpler species as $\mathrm{H}_{2} \mathrm{~S}$ and $\mathrm{NH}_{3}$ are relatively abundant in comets [15] as well as in the ISM. The microwave spectrum of $\mathrm{NH}_{2} \mathrm{SH}$ was measured by Lovas et al. [36] and was refit by one of us (SS). We did not search specifically for $\mathrm{NH}_{2} \mathrm{SH}$. However, a transition expected to be strong at the temperatures of interstellar clouds was covered in our observations targeted toward other molecules. This enables us to place upper limits on the abundance of $\mathrm{NH}_{2} \mathrm{SH}$ in several sources (Table $6)$.

\section{Results}

From the intensities of the emission lines which we have detected, or the corresponding upper limits, we now wish to determine the column density or its limit for each molecular species toward each source for which we have data.

\subsection{Aziridine (ethylenimine, $c-\mathrm{C}_{2} \mathrm{H}_{4} \mathrm{NH}$ )}

As discussed in Section 2.1, we have detected two lines in several sources which may be assignable to aziridine. Assuming a rotational temperature of $30-50 \mathrm{~K}$ and optically thin (unsaturated) emission, the standard relationship between observed line intensity and the corresponding column density (e.g. [57]) shows that both of these lines are consistent with aziridine column densities of order $10^{14} \mathrm{~cm}^{-2}$ for the two hot cores, G327.3 and G10.47. However, there are other lines that at first glance should have been detected but are not seen, most notably the $5_{05}-4_{14} / 5_{15}-4_{04}$ doublet at $142375 \mathrm{MHz}$, but also, e.g. the $3_{03}-2_{12}$ and $3_{13}-2_{02}$ lines at 88964.3 and $88739.7 \mathrm{MHz}$, respectively (Table 4). The lack of emission features at these frequencies might imply an aziridine abundance 2-5 times lower than the one inferred from the two detected lines, although part of the absence of the $142 \mathrm{GHz}$ feature may be due to blending with the nearby $12-11$ line of $\mathrm{OC}^{34} \mathrm{~S}$. The remaining discrepancy may be explained in terms of our frequency-dependent angular resolution (beam dilution). So far we have assumed that the emission from aziridine has an angular extent on the sky that completely fills the antenna beam pattern at all our observing frequencies. Since hot cores are intrinsically compact objects, this may well not be true. Thus, in a recent study of G327, Gibb et al. conclude that the emission from several of the more complex organics is confined to a region much smaller than the beam sizes listed in Table 2 [20]. A similar situation clearly holds for other similar source regions (e.g. [18]). If the region responsible for our putative aziridine emission is much smaller than the antenna main-beam, the telescope angular resolution (gain) is a factor of 2.5 lower at $142 \mathrm{GHz}$ than at $233 \mathrm{GHz}$, and a factor of 6.5 lower at 89 $\mathrm{GHz}$ than at $233 \mathrm{GHz}$. Hence, this effect could indeed explain the lack of emission at these lower frequencies. But this also implies that the detected line at $86312 \mathrm{MHz}$ may be enhanced by blending with emission from an unidentified species.

Table 6

Thiohydroxylamine upper limits ${ }^{\mathrm{a}}$

\begin{tabular}{|c|c|c|c|c|}
\hline Source & $T_{\mathrm{mb}}(\mathrm{mK}: 1 \sigma \mathrm{rms}) 3_{1,3^{-2}} 2_{1,2}$ & Linewidth $\left[\mathrm{km} \mathrm{s}^{-1}\right]$ & $T_{\mathrm{ex}}[\mathrm{K}]$ & $\mathrm{N}\left(\mathrm{NH}_{2} \mathrm{SH}\right)\left[\times 10^{13} \mathrm{~cm}^{-2}\right]$ \\
\hline $\mathrm{G} 327.3-0.6$ & 6.0 & 5.0 & $20-50$ & $2.3-4.5$ \\
\hline NGC $6334 \mathrm{~F}$ & 11.0 & 5.0 & $20-50$ & $4.5-8.2$ \\
\hline $\mathrm{G} 10.47+0.03$ & 12.0 & 5.0 & $20-50$ & $4.9-8.7$ \\
\hline $\mathrm{G} 31.41+0.31$ & 11.0 & 5.0 & $20-50$ & $4.5-8.2$ \\
\hline $\mathrm{G} 34.3+0.2$ & 11.0 & 5.0 & $20-50$ & $4.5-8.2$ \\
\hline
\end{tabular}

\footnotetext{
a Note: upper limits to the intensity of the indicated transition given in column 2. Upper limits on column density in column 5 are calculated for the estimated line width in column 3 and the range of temperatures in column 4 .
} 

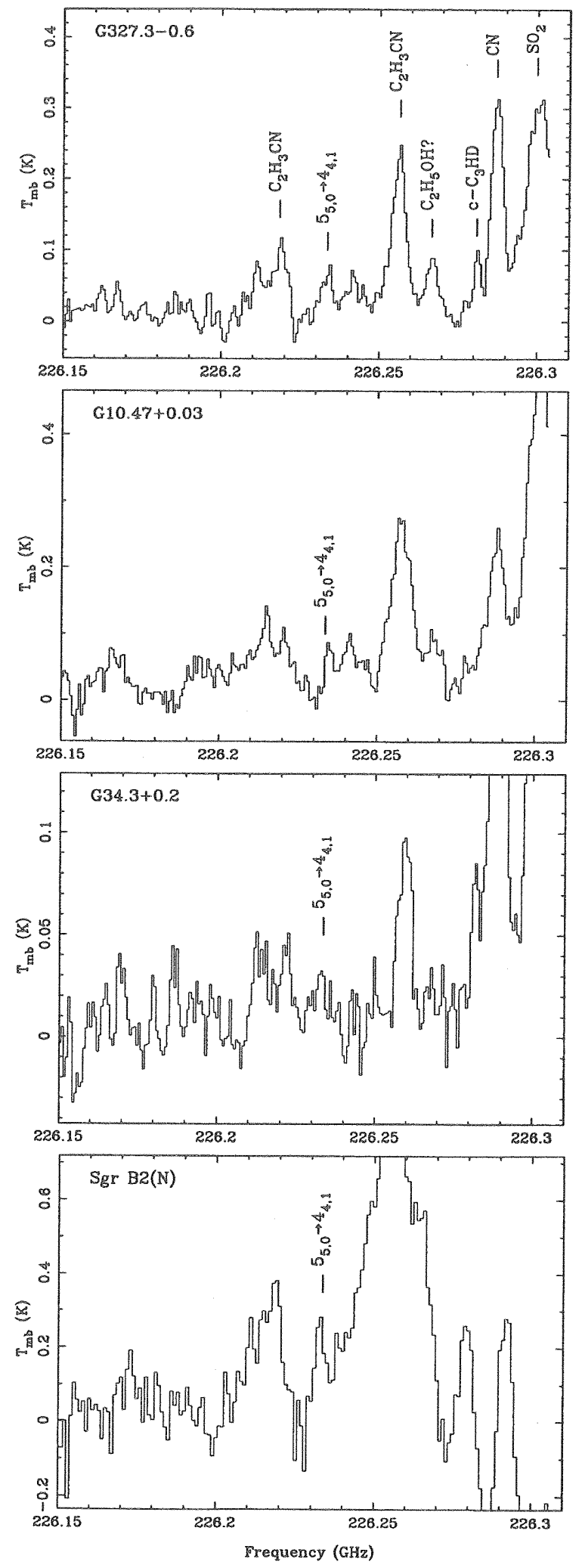

Fig. 2.
In summary, the observations are consistent with the assignment of the emission line at $226233.4 \mathrm{MHz}$ in several sources to the $5_{50}-4_{41}$ line of aziridine, but further observations are needed to confirm the identification of this molecule in the interstellar medium.

\subsection{Propenal (acrolein, $\mathrm{CH}_{2} \mathrm{CHCHO}$ )}

In its simplest form a rotation diagram analysis plots observed line intensities versus energy of the upper level of each transition, with the intensities normalized by intrinsic line strength in such a way that the plot will be linear if the population distribution is Boltzmann [e.g. [18,58]]. The slope of this line gives the rotational (Boltzmann) temperature, while the intercept is related to the column density. Using such an analysis for the 6 emission lines which coincide with transitions of propenal (Fig. 6), we obtain a reasonable fit to a rotation temperature of $78 \pm 20 \mathrm{~K}$ in $\mathrm{G} 327.3-0.6$ and $96 \pm 28 \mathrm{~K}$ in $\mathrm{SgrB} 2 \mathrm{~N}$, with corresponding column densities of $1.5(10)^{14}$ and $8.7(10)^{14} \mathrm{~cm}^{-2}$, respectively, in the two sources. Using this information, we calculated the expected line strengths for other propenal transitions within our observed spectral regions. These values for $T_{\text {rot }}$ and column density predict intensities of the propenal transitions at $88.523,97.263$, and $107.529 \mathrm{GHz}$ (see Table 3 and Table 5) up to an order of magnitude stronger than the 6 lines mentioned above, so that these undetected lines should have been easily observable in our spectra. Although very nonequilibrium intensities are sometimes observed in hot core sources (e.g. stronger than expected emission from weak, $b$-type transitions, perhaps excited by infrared radiation $[18,56])$, our failure to detect the propenal transitions with larger A-coefficients leads us to claim only a possible identification of propenal in our sources. We therefore present our results as upper limits to the column density of propenal in Table 7.

Fig. 2. Spectra at $226.2 \mathrm{GHz}$ for several hot core sources (labeled in upper left of each panel), showing the tentative detection of the $5_{50}-4_{41}$ transition of aziridine. Intensity scale is given as main beam antenna temperature in Kelvin (see text). Other transitions in the band may be assigned to $\mathrm{SO}_{2}$, $\mathrm{CH}_{2} \mathrm{CHCN}, \mathrm{CN}$, and possibly $\mathrm{c}-\mathrm{C}_{3} \mathrm{HD}$ and ethanol $[59,60]$. 
This example of propenal illustrates the importance of observing multiple transitions of a new molecular species, and obtaining a consistent picture of line intensities as a function of expected excitation, before claiming the detection of a new interstellar species. The case of propenal is particularly difficult, because of the large number of transition frequencies which fall into our observed bands.

\subsection{Other molecular species}

For cyclopropenone, furan, hydroxyethanal, and ethenol we wish to determine an upper limit on the column density along a given line of sight, using the upper limits on the intensity of several transitions. For this purpose we assumed a rather large column density for that species and a uniform excitation temperature (the same for all transitions), and then calculated the corresponding antenna temperatures. Initially such antenna temperatures were higher than our observed limits. We then lowered the column density until the strongest calculated transition had an antenna temperature three times the observed rms noise in the spectrum, at which point all the other transitions had predicted antenna temperatures well below their corresponding noise level (note that this noise level typically differed somewhat among the observed transitions, which may have been observed with different receivers at different times). The procedure was then repeated for another choice of excitation temperature, as indicated in Table 7; the range of excitation temperatures was chosen to match a reasonable range of values for the particular source, as determined from the corresponding excitation of known molecular constituents of that source (see references in Section 1 above). The same procedure, but for only the single observed transition, was followed for $\mathrm{NH}_{2} \mathrm{SH}$ (Table 6).

\section{Discussion}

In comparing the present results with those of previous investigations or with chemical models, it is desirable to estimate the relative abundance,

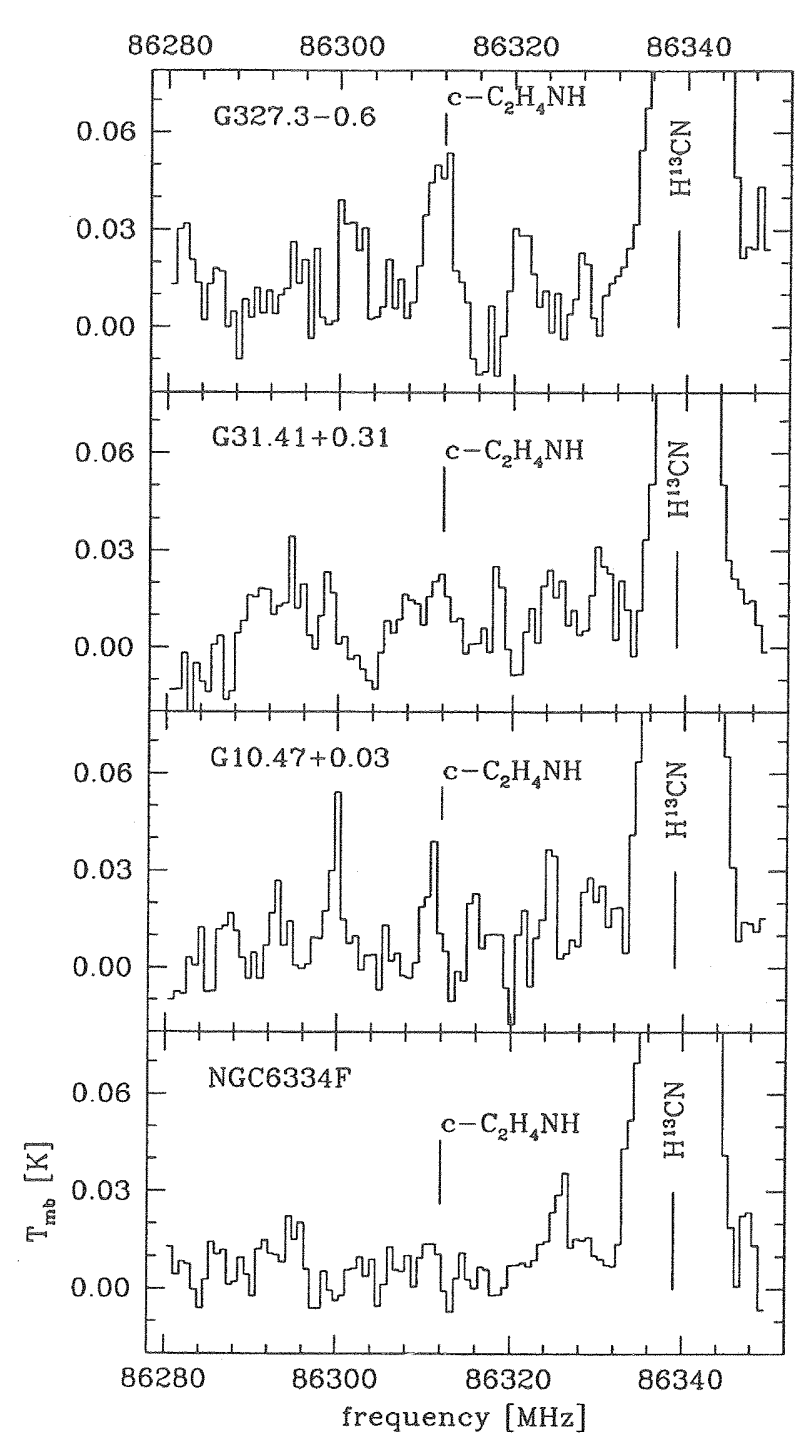

Fig. 3. Spectra at $86.3 \mathrm{GHz}$ for the hot core sources labeled in upper left of each panel, showing the tentative detection of the $2_{11}-1_{01}$ transition of aziridine $\left(\mathrm{c}-\mathrm{C}_{2} \mathrm{H}_{4} \mathrm{NH}\right)$. Intensity scale is antenna temperature in Kelvin (see text). The $J=1-0$ transition of $\mathrm{H}^{13} \mathrm{CN}$ is in the band.

or limit on the relative abundance, of each species with respect to $\mathrm{H}_{2}$, which is by far the most abundant constituent of dense interstellar clouds. As discussed in detail elsewhere $[9,18]$, this is not a simple task. Normally the fractional abundance of species $X$, symbolized by $[X]$, is approximated by the average along the line of sight given by the ratio of column densities $[X]=\mathrm{N}(X) / \mathrm{N}\left(\mathrm{H}_{2}\right)$. Since the non-polar $\mathrm{H}_{2}$ is not easily detectable, $\mathrm{N}\left(\mathrm{H}_{2}\right)$ is 
usually estimated by assuming an abundance for the principal tracer of cloud material, $\mathrm{CO}$; measuring the column density of one of its rarer isotopomers such as $\mathrm{C}^{18} \mathrm{O}$ or $\mathrm{C}^{17} \mathrm{O}$, whose transitions are assumed to be optically thin (unsaturated); and assuming a local isotopic ratio for ${ }^{18} \mathrm{O} /{ }^{16} \mathrm{O}$ or ${ }^{17} \mathrm{O} /{ }^{16} \mathrm{O}$.

The values of $\mathrm{N}\left(\mathrm{H}_{2}\right)$ reported in Table 2 are

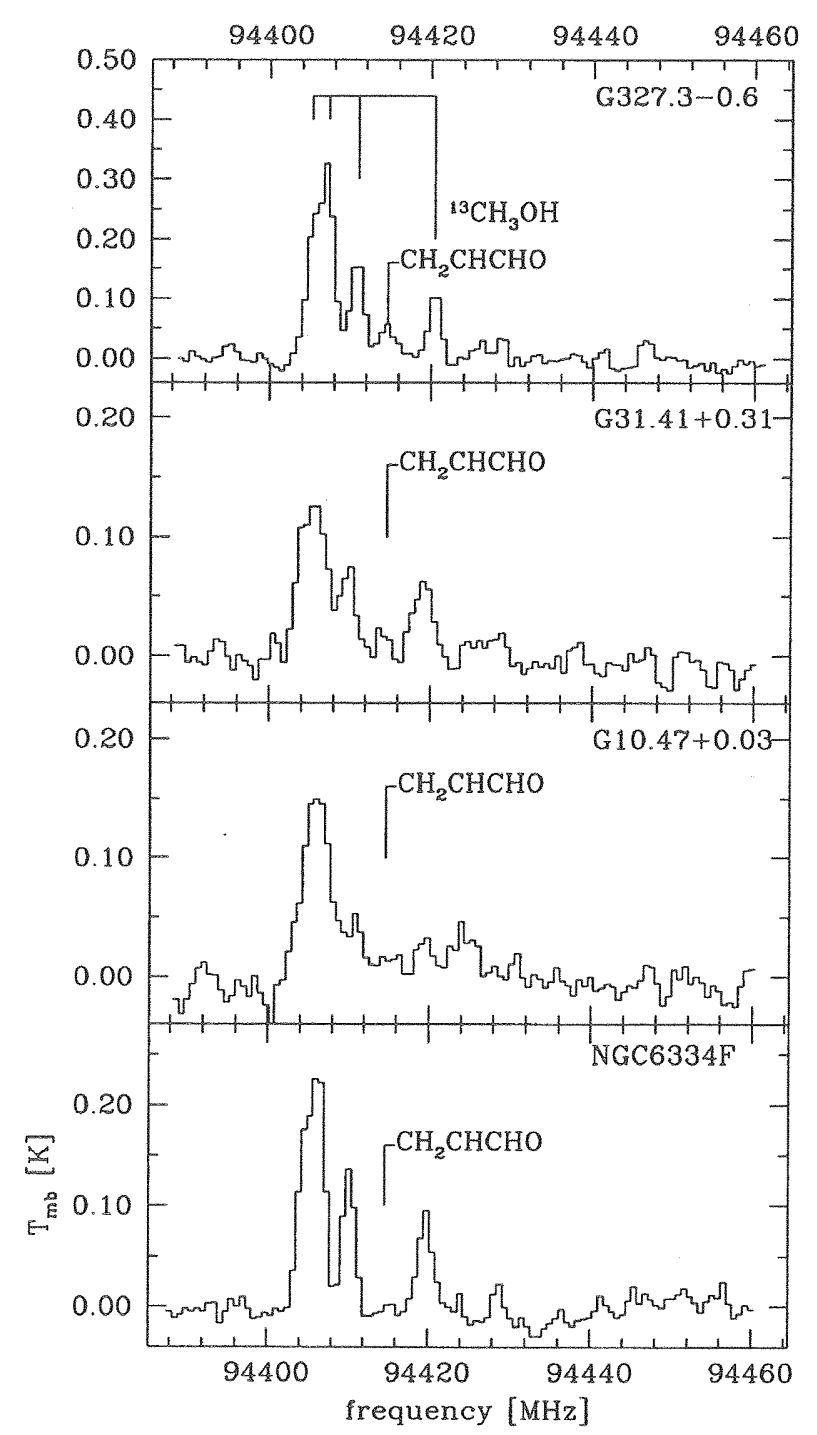

Fig. 4. Spectra at $94.4 \mathrm{GHz}$ for several hot core sources (labeled in upper right of each panel), with the frequency of the $21_{1,20}-21_{1,21}$ transition of trans-propenal $\left(\mathrm{C}_{2} \mathrm{H}_{3} \mathrm{CHO}\right)$ indicated. Intensity scale is given as antenna temperature in Kelvin. Frequency of several symmetry components of the 2-1 transition of 13-carbon methanol are indicated in the top panel.
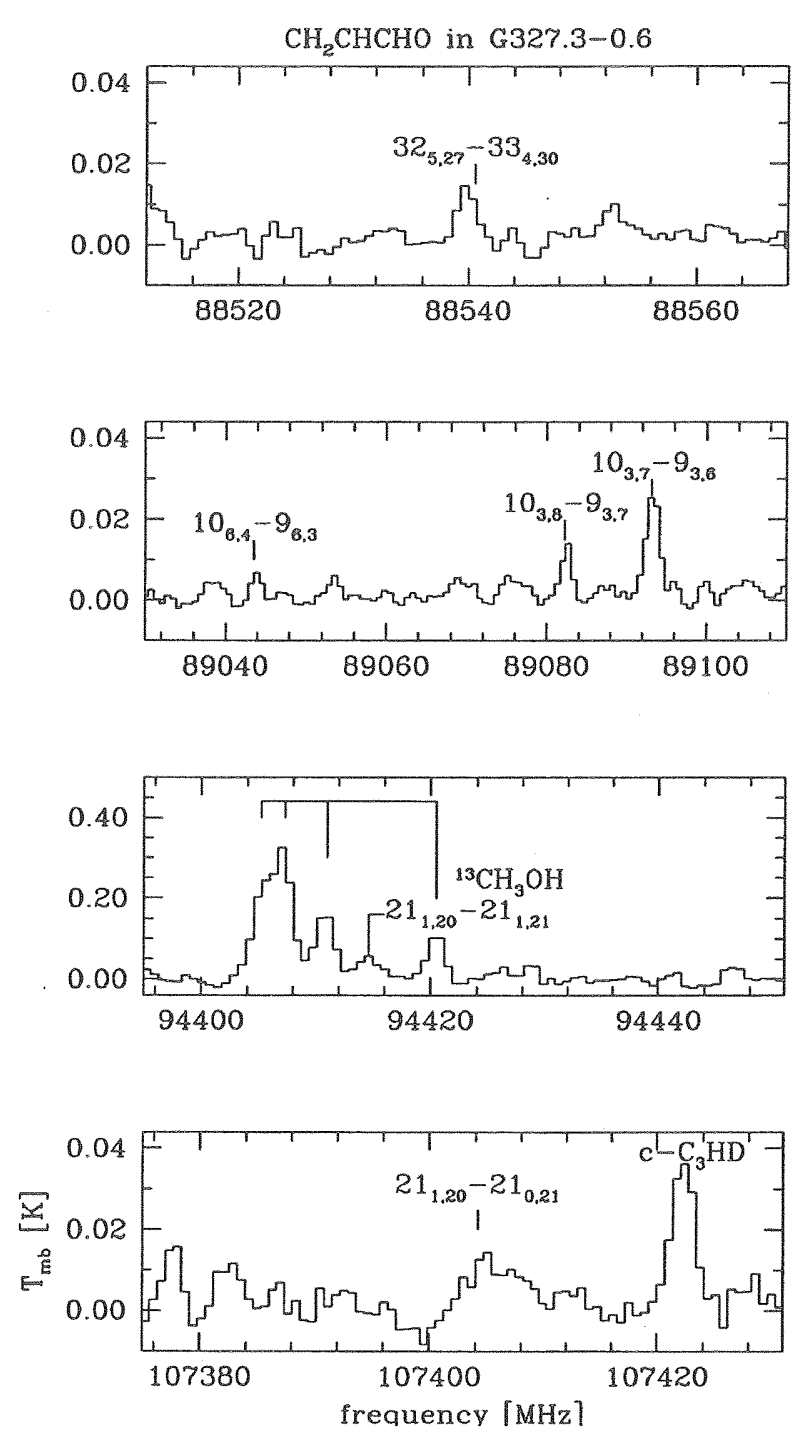

Fig. 5. Spectra showing 6 transitions of trans-propenal, indicated by their quantum numbers (see Table 3 ), in the hot core region G327.3-0.6. Intensity scale is given as antenna temperature in Kelvin (see text). Also indicated are transitions of ${ }^{13} \mathrm{CH}_{3} \mathrm{OH}$ and cyclopropenylidene- $\mathrm{d}_{1}$.

'beam averages'; that is, they are averages over the angular region defined by the resolution of the telescope at the observed frequency. They have been derived from observations of the $\mathrm{CO}$ isotopomer listed in column 7 of Table 2. Some of our observed clouds contain compact, hot, dense cores from which the emission of complex molecules may be enhanced. If such cores are smaller than our angular resolution, we may underestimate the abundance of molecular species 
that are present only in such compact regions (cf. $[18,20])$. Likewise, our beam-averaged upper limits for such species will be lower than the limits which might actually apply to the core itself.

Since we do not have measurements of the CO column densities at the high angular resolutions (of order a few arcsec) which would correspond to such hot core sizes, the abundance upper limits which we shall compute will be beam averages (but see the discussion for aziridine below). Dividing the column density upper limits $\mathrm{N}(X)$ from Table 6 and Table 7 by the values of $\mathrm{N}\left(\mathrm{H}_{2}\right)$ for each source region from Table 2, we may obtain upper limits for the beam-averaged fractional abundance $[X]$ of each molecular species in each source. These are given in Table 8 . Note that we have included propenal in Table 8 , because of the uncertainties involving the possible propenal detections described in Section 3.2. In most cases the principal source of uncertainty in the resulting abundances arises from uncertainties in $\mathrm{N}\left(\mathrm{H}_{2}\right)$, which can be as much as an order of magnitude. For comparison with the values in Table 8 , we may note that such organic molecules as ethanol $\left(\mathrm{CH}_{3} \mathrm{CH}_{2} \mathrm{OH}\right)$ or methyl formate $\left(\mathrm{CH}_{3} \mathrm{OCHO}\right)$ have abundances in hot core sources in the range $10^{-9}-10^{-8}$ (e.g. [20]).

For aziridine the situation is more complex. Assuming that any aziridine emission would be extended relative to our angular resolution at all observed frequencies (i.e. no beam dilution, consistent with our treatment of the other molecular species described above) and that the energy level populations obeyed a Boltzmann distribution, our failure to detect lines at the frequencies of several aziridine transitions would imply that the lines at 226.2 and $86.3 \mathrm{GHz}$ must be assigned to an unknown carrier(s). The intensity upper limits in Table 4 would then allow us to deduce the column density upper limits given in the second column of Table 9. On the other hand, the $226.2 \mathrm{GHz}$ line can be assigned to the $5_{50}-4_{41}$ transition of

Table 7

Column density upper limits ${ }^{\mathrm{h}}$

\begin{tabular}{|c|c|c|c|c|c|}
\hline Source & $\begin{array}{l}\mathrm{N}\left(\mathrm{CH}_{2} \mathrm{CHOH}\right. \\
{\left[10^{14} \mathrm{~cm}^{-2}\right]}\end{array}$ & $\begin{array}{l}\mathrm{N}\left(\mathrm{c}-\mathrm{C}_{3} \mathrm{H}_{2} \mathrm{O}\right) \\
{\left[10^{12} \mathrm{~cm}^{-2}\right]}\end{array}$ & $\begin{array}{l}\mathrm{N}\left(\mathrm{c}-\mathrm{C}_{4} \mathrm{H}_{4} \mathrm{O}\right) \\
\quad\left[10^{14} \mathrm{~cm}^{-2}\right]\end{array}$ & $\begin{array}{c}\mathrm{N}\left(\mathrm{CH}_{2} \mathrm{OHCHO}\right) \\
{\left[10^{12} \mathrm{~cm}^{-2}\right]}\end{array}$ & $\begin{array}{c}\mathrm{N}\left(\mathrm{CH}_{2} \mathrm{CHCHO}\right) \\
{\left[10^{12} \mathrm{~cm}^{-2}\right]}\end{array}$ \\
\hline TMC $-1(C P)^{a, e}$ & $0.3^{1}-0.2^{1}$ & $1.7^{7}-0.8^{7}$ & $0.1^{11}-0.2^{11}$ & $0.9^{15}-0.8^{15}$ & $\ldots$ \\
\hline Orion $\mathrm{KL}^{\mathrm{c} \cdot \mathrm{g}}$ & $1.9^{2}-2.3^{6}$ & $2.7^{9}-4.7^{9}$ & $2.9^{11}-5.9^{14}$ & $14.0^{15}-41 .^{15}$ & $\ldots$ \\
\hline Orion $3 N^{b, f}$ & $0.6^{1}-1.3^{1}$ & $3.6^{8}-5.1^{8}$ & $0.8^{11}-3.0^{11}$ & $4.9^{15}-13.0^{15}$ & $\ldots$ \\
\hline $\mathrm{G} 327.3-0.6^{\mathrm{cg} g}$ & $1.5^{3}-1.2^{5}$ & $1.3^{10}-2.1^{10}$ & $1.0^{12}-1.4^{13}$ & $\ldots$ & $5.3^{16}-6.9^{16}$ \\
\hline $\operatorname{L} 134 \mathrm{~N}(\mathrm{C})^{\mathrm{a}, \mathrm{e}}$ & $0.2^{1}-0.1^{1}$ & $1.9^{8}-0.7^{8}$ & $0.1^{11}-0.2^{11}$ & $0.6^{15}-0.6^{15}$ & $\ldots$ \\
\hline IRS $16293^{\mathrm{c}, \mathrm{g}}$ & $1.3^{2}-1.5^{2}$ & $8.7^{8}-19.0^{8}$ & $85.0^{14}-7.1^{14}$ & $\ldots$ & $\ldots$ \\
\hline NGC $6334 F^{c, g}$ & $1.1^{3}-1.8^{3}$ & $1.3^{10}-2.1^{10}$ & $1.0^{12}-1.4^{13}$ & $\ldots$ & $5.4^{16}-7.2^{16}$ \\
\hline $\operatorname{SgrB} 2 N^{\mathrm{d}, \mathrm{g}}$ & $5.8^{3}-6.7^{4}$ & $2.7^{10}-4.2^{10}$ & $2.0^{12}-2.9^{13}$ & $\ldots$ & $19.0^{16}-22.0^{16}$ \\
\hline $\mathrm{G} 10.47+0.03^{\mathrm{c}, \mathrm{g}}$ & $1.9^{3}-2.3^{5}$ & $\ldots$ & $\ldots$ & $\ldots$ & $11.0^{17}-12.0^{17}$ \\
\hline W33 $\mathrm{A}^{\mathrm{c}, \mathrm{g}}$ & $1.0^{2}-1.2^{2}$ & $1.6^{9}-2.6^{9}$ & $99.14-9.014$ & $\ldots$ & $\ldots$ \\
\hline $\mathrm{G} 31.41+0.31^{\mathrm{c}, \mathrm{g}}$ & $1.9^{3}-2.1^{5}$ & $\ldots$ & $\ldots$ & $\ldots$ & $11.0^{17}-12.0^{17}$ \\
\hline $\mathrm{G} 34.3+0.2^{\mathrm{c.g}}$ & $1.9^{3}-2.1^{5}$ & $\ldots$ & $\ldots$ & $\ldots$ & $\ldots$ \\
\hline
\end{tabular}

${ }^{a}$ Assuming linewidth of $0.5 \mathrm{~km} \mathrm{~s}^{-1}$.

${ }^{\mathrm{b}}$ Assuming linewidth of $3.0 \mathrm{~km} \mathrm{~s}^{-1}$.

${ }^{\mathrm{c}}$ Assuming linewidth of $5.0 \mathrm{~km} \mathrm{~s}^{-1}$.

${ }^{d}$ Assuming linewidth of $10.0 \mathrm{~km} \mathrm{~s}^{-1}$.

${ }^{\text {e}}$ Assuming excitation temperature range $5 \mathrm{~K}$ (first entry) to $10 \mathrm{~K}$ (s).

${ }^{\mathrm{f}}$ Assuming excitation temperature range $10 \mathrm{~K}$ (first entry) to $30 \mathrm{~K}$ (s).

${ }^{\mathrm{g}}$ Assuming excitation temperature range $20 \mathrm{~K}$ (first entry) to $50 \mathrm{~K}(\mathrm{~s}$ ).

${ }^{\text {h }}$ Note: All values are $3 \sigma$ upper limits, although propenol $\left(\mathrm{CH}_{2} \mathrm{CHCHO}\right)$ may possibly have been detected (see Section 3.2). (1) from transition $2_{1,2}-1_{0,1} ;(2)$ from transition $4_{2,3}-3_{1,2} ;$ (3) from transition $5_{1,4}-4_{1,3} ;$ (4) from transition $6_{3,4}-6_{2,5} ;(5)$ from transition $8_{1.7}-8_{0,8} ;(6)$ from transition $12_{1,12}-11_{0.11} ;(7)$ from transition $5_{1,4}-4_{1,3} ;(8)$ from transition $6_{0,6}-5_{0,5} ;(9)$ from transition $7_{1,6}-6_{1,5} ;(10)$ from transition $8_{0.8}-7_{0,7}$; (11) from transition $2_{0,2}-1_{0.1} ;$; (12) from transition $9_{0,9}-8_{0,8}$; (13) from transition $11_{0.11}-10_{0.10}$; (14) from transition $22_{0,22}-21_{0,21} ;(15)$ from transition $4_{1,3}-4,0,4 ;(16)$ from transition $10_{0,10}-9_{0,9} ;(17)$ from transition $11_{0,11}-10_{0,10}$. 


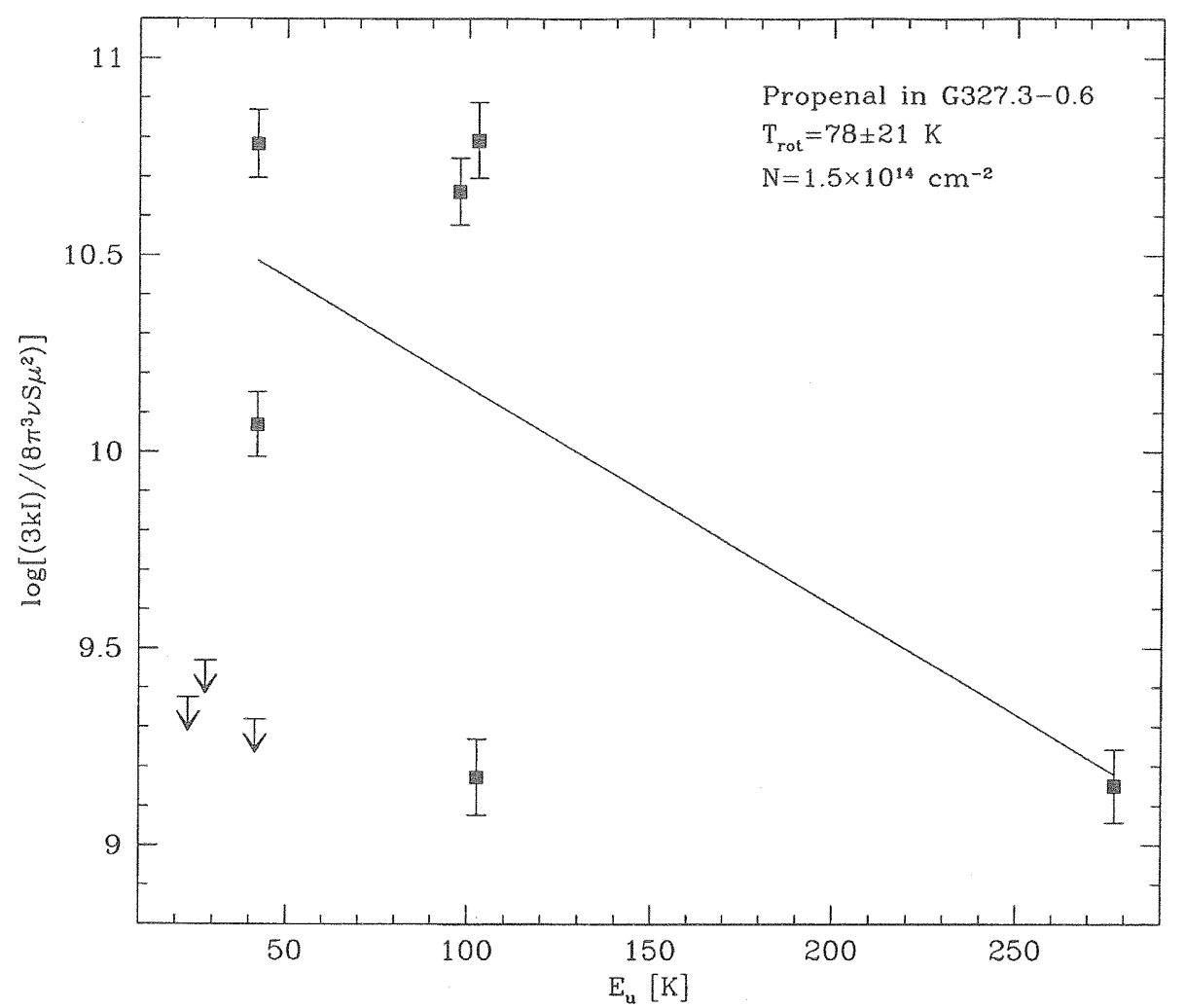

Fig. 6. Rotation diagram (see text), showing the 6 apparently detected transitions of trans-propenal in the hot core source G327.3 - 0.6. $E_{\mathrm{u}}$ is the energy of the upper level of the transition in temperature units, $I$ is the integrated intensity of the observed line, $k$ is Boltzmann's constant, $\mu$ is the relevant component of the molecular dipole moment, and $v$ and $S$ are the frequency and intrinsic line strength of the transition (see the discussion of rotation diagrams in [18]). The fit to the data points, which yields the propenal column density $N$ and rotation temperature $T_{\text {rot, }}$, ignores the upper limits indicated by the downward-pointing arrows.

aziridine in a consistent manner, if the aziridine emission at $86 \mathrm{GHz}$ is significantly beam-diluted, as would be expected for a hot core. In column three of Table 9 we calculate column densities on the assumption that the aziridine emission comes from a region of the same angular size as our 226 GHZ beam size (about 20 arcsec), using $T_{\text {rot }}=50$ $\mathrm{K}$. The corresponding abundances are listed in column 4. Aziridine abundances in the range $1-$ $5 \times 10^{-10}$ with respect to $\mathrm{H}_{2}$ are deduced. This is about the same as the values found for the abundance of the related species oxirane $\left(c-\mathrm{C}_{2} \mathrm{H}_{4} \mathrm{O}\right)$ in several hot cores [21].

It must be noted that the aziridine column densities in the innermost part of compact hot cores could be considerably higher than the values in Table 9, although the corresponding column densities for $\mathrm{H}_{2}$ would also be higher. For example, if the emission in the case of the source G327 were confined to a core of angular size about 2 arcsec, as suggested by results for some other large organic species [20], the column density of aziridine would be of order $10^{16} \mathrm{~cm}^{-2}$, and the abundance relative to $\mathrm{H}_{2}$ of order $10^{-9}$ (the values do not simply scale with the beam area, since the aziridine line becomes saturated). The scaling with rotational temperature goes basically as the partition function, and is thus not a large factor given the other uncertainties.

The case for the tentative detection of interstellar aziridine is stronger that that for propenal for the following reasons. We detect emission lines in several sources at the frequencies of what are expected to be the two strongest aziridine transitions in our observed frequency bands. The failure to detect other aziridine transitions can reasonably be the result of our frequency-dependent angular resolution (beam dilution) towards small, 
hot core sources. In contrast, although we detect emission features that might be assignable to six different propenal transitions, we do not see transitions that would reasonably be expected to be considerably stronger. Since all the propenal transitions in question are in the same general frequency range, beam dilution can not explain the discrepancies.

Finally, we should comment on the recent reported detection of hydroxyethanal [73] in the Galatic center cloud $\operatorname{Sgr} B 2(N)$. Since we did not search for hydroxyethanal in this source, no direct comparison is possible. We note, however, that our upper limits in Table 8 for the sources which we did observe are at approximately the same level (a few parts in $10^{10}$, using the $\mathrm{H}_{2}$ column density from Table 2) as the claimed detection in $\operatorname{Sgr} B 2(N)$.

\section{Conclusion}

We have surveyed a number of interstellar clouds, including both 'hot core' sources where massive stars are forming and quiescent cloud regions, for rotational transitions from a number of previously undetected molecular species. We report the detection of several emission lines that correspond in frequency to transitions of propenal $\left(\mathrm{CH}_{2} \mathrm{CHCHO}\right)$ and aziridine $\left(\mathrm{c}-\mathrm{C}_{2} \mathrm{H}_{4} \mathrm{NH}\right)$. In the case of aziridine, for reasonable source temperatures the 2 detected lines are expected to be the 2 strongest in our observed frequency bands, and we therefore claim the first, tentative, astronomical identification of aziridine. The evidence is strongest in the hot cores G327.3-0.6 and $\mathrm{G} 10.47+0.03$. Further observations of other aziridine transitions are needed to confirm this result, which implies abundances of the same order as have been reported for oxirane in similar sources (by number of molecules, a few parts in $10^{10}$ relative to molecular hydrogen [21]).

For propenal we have only a possible identification. Although some 6 emission features in our spectra of $\mathrm{G} 327.3$ and 4 in $\operatorname{SgrB2}(\mathrm{N})$ coincide with propenal transitions, other such transitions are not observed. If propenal is indeed responsible for the detected lines, unusual and not understood excitation conditions are present. Observations of intrinsically stronger transitions, at higher frequencies than our present $3 \mathrm{~mm}$ data, would be helpful in determining whether propenal is indeed present in interstellar clouds.

Table 8

Abundance upper limits relative to $\mathrm{H}_{2}{ }^{\mathrm{a}}$

\begin{tabular}{|c|c|c|c|c|c|c|}
\hline Source & $\begin{array}{l}\mathrm{CH}_{2} \mathrm{CHOH} \\
\left(\times 10^{10}\right)\end{array}$ & $\begin{array}{l}\mathrm{c}-\mathrm{C}_{3} \mathrm{H}_{2} \mathrm{O} \\
\left(\times 10^{10}\right)\end{array}$ & $\begin{array}{l}\mathrm{c}-\mathrm{C}_{4} \mathrm{H}_{4} \mathrm{O} \\
\left(\times 10^{10}\right)\end{array}$ & $\begin{array}{l}\mathrm{CH}_{2} \mathrm{OHCHO} \\
\left(\times 10^{10}\right)\end{array}$ & $\begin{array}{l}\mathrm{CH}_{2} \mathrm{CHCHO} \\
\left(\times 10^{10}\right)\end{array}$ & $\begin{array}{l}\mathrm{NH}_{2} \mathrm{SH} \\
\left(\times 10^{10}\right)\end{array}$ \\
\hline TMC-1 & 10 & 0.8 & 10 & 0.5 & & \\
\hline Orion $\mathrm{KL}$ & 20 & 0.5 & 60 & 4 & & \\
\hline Orion $3 / \mathrm{N}$ & 30 & 1 & 60 & 3 & & \\
\hline $\mathrm{G} 327.3$ & 5 & 0.07 & 5 & & 0.2 & 2 \\
\hline L134N(C) & 9 & 0.9 & 10 & 0.3 & & \\
\hline IRS16293 & 8 & 1 & 400 & & & \\
\hline NGC6334 & 9 & 0.1 & 7 & & 0.4 & 4 \\
\hline SgrB2 N & 2 & 0.01 & 1 & & 0.07 & \\
\hline G10.47 & 20 & & & & 1 & 9 \\
\hline W33A & 2 & 0.03 & 200 & & & \\
\hline G31.41 & 10 & & & & 0.6 & 4 \\
\hline G34.3 & 7 & & & & & 3 \\
\hline
\end{tabular}

${ }^{\text {a }}$ Note: values are $3 \sigma$ upper limits to the fractional abundance by number, as defined for species $X$ by the ratio of column densities, $\mathrm{N}(X) / \mathrm{N}\left(\mathrm{H}_{2}\right)$; see, however, Section 3.1, regarding the possible detection of $\mathrm{CH}_{2} \mathrm{CHCHO}$. All values are multiplied by $10^{10}$. Molecules of similar complexity such as ethanol $\left(\mathrm{CH}_{3} \mathrm{CH}_{2} \mathrm{OH}\right)$ or methyl formate $\left(\mathrm{CH}_{3} \mathrm{OCHO}\right)$ have abundances in hot core sources in the range $10^{-9}-10^{-8}$ (e.g. [20]). 
Table 9

Abundance of aziridine relative to $\mathrm{H}_{2}{ }^{\mathrm{a}}$

\begin{tabular}{|c|c|c|c|}
\hline Source & $\mathrm{N}\left(\mathrm{c}-\mathrm{C}_{2} \mathrm{H}_{4} \mathrm{NH}\right)$ (beam-ave) $\left(10^{13} \mathrm{~cm}^{-2}\right)$ & $\mathrm{N}\left(\mathrm{c}-\mathrm{C}_{2} \mathrm{H}_{4} \mathrm{NH}\right)$ (small source) $\left(10^{13} \mathrm{~cm}^{-2}\right)$ & Abundance $\left(\times 10^{10}\right)$ \\
\hline G327.3 & $<3-6$ & 15 & 5 \\
\hline NGC6334 & $<3-6$ & & $<3$ \\
\hline SgrB2N & $\leq 30-60$ & & $1 ?$ \\
\hline $\mathrm{G} 10.47$ & $<6-9$ & 5 & 5 \\
\hline G31.41 & $<3-6$ & & $<3$ \\
\hline G34.3 & $\leq 3-6$ & & $1 ?$ \\
\hline
\end{tabular}

${ }^{a}$ Note: Column 2 lists $3 \sigma$ upper limit on beam averaged column density, for rotational temperatures of $30 \mathrm{~K}$ (left) or $50 \mathrm{~K}$ (right). Column 3 lists column density assuming $5_{50}-4_{41}$ line may be assigned to aziridine, implying a source size $\leq 20^{\prime \prime}$. Column 4 gives the abundance, $\mathrm{N}\left(\mathrm{c}-\mathrm{C}_{2} \mathrm{H}_{4} \mathrm{NH}\right) / \mathrm{N}\left(\mathrm{H}_{2}\right)$, multiplied by $10^{10}$, based on column 3 if value given, otherwise on column 2 .

To our knowledge, there are no published chemical models which include calculations of the expected abundance of aziridine or propenal in interstellar clouds, probably because these species have not hitherto been discussed as potential cloud constituents. Nonetheless, it seems likely that they would be produced by a combination of gas phase reactions and processes in icy grain mantles, such as those discussed in connection with hot cores by Tielens and Charnley [72]. Their calculated abundances, and those of the species for which we obtained only upper limits, would depend, however, on reaction rates and branching ratios for which data is limited or absent, particularly at the temperatures relevant to the interstellar medium. Given simply the relative cosmic abundance of nitrogen to oxygen (about 1:8) and the uncertainties in the measured astronomical abundance of oxirane, the presence of aziridine in hot cores at about our estimated abundance is reasonable.

We also obtained upper limits on the abundance of furan $\left(\mathrm{c}-\mathrm{C}_{4} \mathrm{H}_{4} \mathrm{O}\right)$, cyclopropenone (c$\left.\mathrm{C}_{3} \mathrm{H}_{2} \mathrm{O}\right)$ hydroxyethanal $\left(\mathrm{CH}_{2} \mathrm{OHCHO}\right)$, thiohydroxylamine $\left(\mathrm{NH}_{2} \mathrm{SH}\right)$, and ethenol $\left(\mathrm{CH}_{2} \mathrm{CHOH}\right)$ in several regions. Our upper limits for hydroxyethanal are at about the same level as a recently claimed detection of this molecule [73]. All these values will help to constrain the chemical processes that are important in dense interstellar clouds. Future attempts to detect these species, or to improve the present abundance limits, should strive for higher angular resolution toward the small hot core regions. Both the Large Mil- limeter Telescope, presently being constructed by the University of Massachusetts and the Mexican Instituto Nacional de Astrofisica, Optica y Electronica [65], and millimeter and submillimeter arrays such as CARMA and ALMA [66] will be important in this context. Observations at submillimeter wavelengths would benefit from larger intrinsic line strengths, at least where system sensitivities comparable to those presently available at $\lambda<1 \mathrm{~mm}$ can be achieved.

\section{Acknowledgements}

The authors are grateful to the staffs at SEST, the NRAO $12 \mathrm{~m}$ telescope, and the NASA DSN for their assistance and expertise in the observations reported here; to M. Ikeda, E. Gibb, and S.-L. Liu for assistance in carrying out the observations and in reducing the data; to P. Bergman and an anonymous referee for helpful discussions; and to Anne Horn for making measurements of the microwave spectrum of hydroxyethanal. The Swedish-ESO Submillimetre Telescope (SEST) is operated jointly by ESO and the Swedish $\mathrm{Na}$ tional Facility for Radio Astronomy, Onsala Space Observatory, at Chalmers University of Technology. The National Radio Astronomy Observatory (NRAO) is a facility of the National Science Foundation, operated under a cooperative agreement by Associated Universities, Inc. This research was supported in part by NASA grants NAG5-7598 (NY Center for Studies of the Origins of Life) and NAG5-8718, by the Swedish 
Natural Science Research Council (NFR), by the Deutsche Forschungsgemeinschaft via Grants SFB 301 and SFB 494, and by special funding from the Ministry of Science of the Land Nordrhein-Westfalen.

\section{References}

[1] W.D. Langer, E.F. van Dishoeck, E.A. Bergin, G.A. Blake, A.G.G.M. Tielens, T. Velusamy, D.C.B. Whittet, in: V. Mannings, A.P. Boss, S.S. Russell (Eds.), Protostars and Planets IV, University of Arizona Press, Tucson, 2000, p. 29.

[2] E.F. Van Dishoeck, G.A. Blake, Ann. Rev. Astron. Astrophys. 36 (1998) 317.

[3] Y.C. Minh, E.F. van Dishoeck, Astrochemistry: From Molecular Clouds to Planetary Systems (IAU Symp. 197), Astron Soc. Pacific Conf. Ser., ASP, San Francisco, 2000

[4] A.G.G.M. Tielens, C. van Kerckhoven, E. Peeters, S. Hony, In: Y.C. Minh, E.F. van Dishoeck (Eds.), Astrochemistry: from Molecular Clouds to Planetary Systems (IAU Symp. 197), Astron. Soc. Pacific Conf. Ser., ASP, San Francisco, 2000, p. 349.

[5] T.W. Hartquist, D.A. Williams, The Chemically Controlled Cosmos, Cambridge University Press, Cambridge, 1995.

[6] C.D. Ball, M.C. McCarthy, P. Thaddeus, Astrophys. J. 528 (2000) L61

[7] S. Green, Ann. Rev. Phys. Chem. 32 (1981) 103.

[8] M.B. Bell, J.K.G. Watson, P.A. Feldman, H.E. Matthews, S.C. Madden, W.M. Irvine, Chem. Phys. Lett. 136 (1987) 588.

[9] W.M. Irvine, F.P. Schloerb, Å. Hjalmarson, E. Herbst, in: D.C. Black, M.S. Matthews (Eds.), Protostars and Planets II, University of Arizona Press, Tucson, 1985, p. 579.

[10] E. Herbst, in: W.F. Wall, A. Carraminana, L. Carrasco, P.F. Goldsmith (Eds.), Millimeter-wave Astronomy: Molecular Chemistry and Physics in Space, Kluwer, Dordrecht, 1999 , p. 341

[11] P. Ehrenfreund, W.A. Schutte, In: Y.C. Minh, E.F. van Dishoeck, Astrochemistry: from Molecular Clouds to Planetary Systems (IAU Symp. 197), Astron Soc. Pacific Conf. Ser., ASP, San Francisco, 2000, p. 135.

[12] J.H. Lacy, J.S. Carr, N.J. Evans, F. Baas, J.M. Achtermann, J.F. Arens, Astrophys. J. 376 (1991) 556.

[13] L.C. Oesterling, S. Albert, F.C. De Lucia, K.V.L.N. Sastry, E. Herbst, Astrophys. J. 521 (1999) 255.

[14] Y. Hoshino, M. Ohishi, K. Akabane, T. Ukai, S. Tsunekawa, K. Takagi, Astro. Phys. 104 (1996) 317 Supplementary.

[15] W.M. Irvine, F.P. Schloerb, J. Crovisier, B. Fegley, M.J. Mumma, in: V. Mannings, A.P. Boss, S.S. Russell (Eds.), Protostars and Planets IV, University of Arizona Press, Tucson, 2000, p. 1159
[16] S.B. Charnley, M.E. Kress, A.G.G.M. Tielens, T.J. Millar, Astrophys. J. 448 (1995) 232.

[17] T.J. Millar, G.H. Macdonald, A.G. Gibb, Astron. Astrophys. 325 (1997) 1163.

[18] A. Nummelin, P. Bergman, ̊. Hjalmarson, P. Friberg, W.M. Irvine, T.J. Millar, M. Ohishi, S. Saito, Astrophys. J. Suppl. 128 (2000) 213.

[19] G.A. Blake, E.C. Sutton, C.R. Masson, T.G. Phillips, Astrophys. J. 315 (1986) 621.

[20] E. Gibb, A. Nummelin, W.M. Irvine, D.C.B. Whittet, P. Bergman, Astrophys. J., (2000) in press.

[21] A. Nummelin, J.E. Dickens, P. Bergman, A Hjalmarson, W.M. Irvine, M. Ikeda, M. Ohishi, Astron. Astrophys. 337 (1998) 275.

[22] L. Olmi, R. Cesaroni, C.M. Walmsley, Astron. Astrophys. 307 (1996) 599.

[23] P. Pratap, J.E. Dickens, R.L. Snell, M.P. Miralles, E.A. Bergin, W.M. Irvine, F.P. Schloerb, Astrophys. J. 486 (1997) 862.

[24] J.E. Dickens, W.M. Irvine, R.L. Snell, E.A. Bergin, F.P. Schloerb, P. Pratap, M.P. Miralles, Astrophys. J., (2000) in press.

[25] G.A. Blake, E.F. van Dishoeck, D.J. Jansen, T.D. Groesbeck, L.G. Mundy, Astrophys. J. 428 (1994) 680.

[26] C. Ceccarelli, A Castets, E. Caux, D. Hollenbach, L. Loinard, S. Molinari, A.G.G.M. Tielens, Astron. Astrophys. 355 (2000) 1129.

[27] E. Gibb, D.C.B. Whittet, W.A. Schutte, A.C.A. Boogert, J.E. Chiar, P. Ehrenfreund, P.A. Gerakines, J.V. Keane, A.G.G.M. Tielens, E.F. van Dishoeck, O. Kerkhof, Astrophys. J. 536 (2000) 347.

[28] H. Ungerechts, E.A. Bergin, P.F. Goldsmith, W.M. Irvine, F.P. Schloerb, R.L. Snell, Astrophys. J. 482 (1997) 245.

[29] J.E. Dickens, W.M. Irvine, M. Ohishi, M. Ikeda, S. Ishikawa, A. Nummelin, $\AA$. Hjalmarson, Astrophys. J. 489 (1997) 753.

[30] A. Nummelin, P. Bergman, Astron. Astrophys. 341 (1999) L.59.

[31] G. Winnewisser, E. Churchwell, C.M. Walmsley, in: G.W. Chantry (Ed.), Modern Aspects of Microwave Spectroscopy, Academic Press, New York, 1979, p. 313.

[32] M. Winnewisser, G. Winnewisser, T. Honda, E. Hirota, Z. Naturforsch. 30 (1975) 1001.

[33] S. Thorwirth, H.S.P. Müller, G. Winnewisser, J. Mol. Spec. 199 (2000) 116.

[34] W.M. Irvine, M. Senay, A.J. Lovell, H.E. Matthews, D. McGonagle, R. Meier, Icarus 143 (1999) 412.

[35] W.M. Irvine, J.E. Dickens, A.J. Lovell, F.P. Schloerb, M. Senay, E.A. Bergin, D. Jewitt, H.E. Matthews, Faraday Disc. 109 (1998) 475.

[36] F.J. Lovas, R.D. Suenram, W.J. Stevens, J. Mol. Spec. 100 (1983) 316

[37] H.E. Matthews, W.M. Irvine, Astrophys. J. 298 (1985) L61.

[38] P. Thaddeus, J.M. Vrtilek, C.A. Gottlieb, Astrophys. J. 299 (1985) L63. 
[39] S.C. Madden, W.M. Irvine, H.E. Matthews, P. Friberg, D.A. Swade, Astron. J. 97 (1989) 1403.

[40] R.D. Brown, P.D. Godfrey, D.M. Cragg, E.H.N. Rice, W.M. Irvine, P. Friberg, H. Suzuki, M. Ohishi, N. Kaifu, M. Morimoto, Astrophys. J. 297 (1985) 302.

[41] M. Ohishi, H. Suzuki, S.-I. Ishikawa, C. Yamada, H. Kanamori, W.M. Irvine, R.D. Brown, P.D. Godfrey, N. Kaifu, Astrophys. J. 380 (1991) L39.

[42] J.C. Guillemin, G. Wlodarczak, J.C. Lopez, J. Demaison, J. Mol. Spec. 140 (1990) 190.

[43] S. Saito, Chem. Phys. Lett. 42 (1976) 399.

[44] W.M. Irvine, J. Ellde'r, ^ Hjalmarson, E. Kollberg, O.E.H. Rydbeck, G.O. Sørensen, B. Bak, H. Svanholt, Astron. Astrophys. 97 (1981) 192.

[45] P.C. Myers, P. Thaddeus, R.A. Linke, Astrophys. J. 241 (1980) 155

[46] M.L. Kutner, D.E. Machnik, K.D. Tucker, R.L. Dickman, Astrophys. J. 242 (1980) 541.

[47] G. Wlodarczak, L. Martinache, J. Demaison, J. Mol. Spec. 127 (1988) 200.

[48] R. Krishnamurthy, G. Arrhenius, A. Eschenmoser, Origins Life Evol. Biosphere 29 (1999) 333.

[49] K.-M. Marstokk, H. Møllendal, J. Molec. Structure 5 (1970) 205.

[50] W.M. Irvine, Space Sci. Revs. 90 (1999) 203.

[51] P. Bergman, Tech. Rpt. 227, School Elec. Computer Eng., Chalmers Univ. Technology, Gothenburg, Sweden, 1992.

[52] F.F.S. van der Tak, E.F. van Dishoeck, N.J. Evans, G.A. Blake, Astrophys. J. 537 (2000) 283.

[53] W.M. Irvine, Origins Life Evol. Biosphere 28 (1998) 365.

[54] J. Ellder, P. Friberg, A. Hjalmarson, B. Höglund, W.M. Irvine, L.E.B. Johansson, H. Olofsson, G. Rydbeck, O.E.H. Rydbeck, Astrophys. J. 242 (1980) L93.

[55] D.M. Mehringer, L.E. Snyder, Y. Miao, F.J. Lovas, Astrophys. J. 480 (1997) L71.

[56] B.E. Turner, Astrophys. J. 76 (1991) 617 Supplementary.

[57] W.M. Irvine, P.F. Goldsmith, А. Hjalmarson, In: D.J. Hollenbach, H.A. Thronson, Interstellar Processes, D. Reidel, Dordrecht, 1987, p. 561.

[58] L.E.B. Johansson, C. Andersson, J. Ellder, P. Friberg, A. Hjalmarson, B. Höglund, W.M. Irvine, H. Olofsson, G. Rydbeck, Astron. Astrophys. 130 (1984) 227.

[59] F.J. Lovas, J. Phys. Chem. Ref. Data 21 (1992) 181.

[60] H.M. Pickett, R.L. Poynter, E.A. Cohen, M.L. Delitsky, J.C. Pearson, H.S.P. Muller, J. Quant. Spectrosc. Rad. Transfer 60 (1998) 883 http://spec.jpl.nasa.gov/.
[61] J. Cernicharo, In: Y.C. Minh and E.F. van Dishoeck, Astrochemistry: from Molecular Clouds to Planetary Systems (IAU Symp. 197), Astron Soc. Pacific Conf. Ser., ASP, San Francisco, 2000, p. 375.

[62] H. Feuchtgruber, F.P. Helmich, E.F. van Dishoeck, C.M. Wright, Astrophys. J. 535 (2000) L111.

[63] S. Thorwirth, R. Gendriesch, H.S.P. Müller, F. Lewen, G. Winnewisse, J. Mol. Spec. 201 (2000) 323.

[64] J. Binney, M. Merrifield, Galactic Astronomy, Princeton University Press, Princeton, NJ, 1998.

[65] J.W.M. Baars, L. Carrasco, F.P. Schloerb, Bull. Amer. Astron. Soc. 31 (1999) 09-15.

[66] J. Mangum, Imaging at Radio through Submillimeter Wavelengths, Astron. Soc. Pacific, San Francisco, 2000.

[67] B.P. van Eijck, E. van Zoeren, J. Mol. Spectrosc. 111 (1985) 138.

[68] A. Bauder, J. Phys. Chem. Ref. Data 8 (1979) 583.

[69] (a) T.H. Dunning, J. Chem. Phys., 90 (1989) 1007; (b) R.A. Kendall, T.H. Dunning, R.J. Harrison, J. Chem. Phys., 96 (1992) 6796; (c) T.H. Dunning, D.E. Woon, J. Chem. Phys., 98 (1993) 1358; (d) T.H. Dunning, D.E. Woon, J. Chem. Phys., 100 (1994) 2975; (e) T.H. Dunning, D.E. Woon, J. Chem. Phys., 103 (1995) 4572.

[70] C. Møller, M.S. Plesset, Phys. Rev. 46 (1934) 618.

[71] Gaussian 98, Revision A.7, M.J. Frisch, G.W. Trucks, H.B. Schlegel, G.E. Scuseria, M.A. Robb, J.R. Cheeseman, V.G. Zakrzewski, J.A. Montgomery, Jr., R.E. Stratmann, J.C. Burant, S. Dapprich, J.M. Millam, A.D. Daniels, K.N. Kudin, M.C. Strain, O. Farkas, J. Tomasi, V. Barone, M. Cossi, R. Cammi, B. Mennucci, C. Pomelli, C. Adamo, S. Clifford, J. Ochterski, G.A. Petersson, P.Y. Ayala, Q. Cui, K. Morokuma, D.K. Malick, A.D. Rabuck, K. Raghavachari, J.B. Foresman, J. Cioslowski, J.V. Ortiz, A.G. Baboul, B.B. Stefanov, G. Liu, A. Liashenko, P. Piskorz, I. Komaromi, R. Gomperts, R.L. Martin, D.J. Fox, T. Keith, M.A. Al-Laham, C.Y. Peng, A. Nanayakkara, C. Gonzalez, M. Challacombe, P.M.W. Gill, B. Johnson, W. Chen, M.W. Wong, J.L. Andres, C. Gonzalez, M. Head-Gordon, E.S. Replogle, J.A. Pople, Gaussian, Inc., Pittsburgh PA, 1998.

[72] A.G.G.M. Tielens, S.B. Charnley, Origins Life Evol. Biosphere 27 (1997) 23.

[73] J.M. Hollis, F.J. Lovas, P.R. Jewell, Astrophys. J. (2000) in press.

[74] D.C.B. Whittet, Dust in the Galactic Environment, Institute of Physics Publishing, Bristol, 1992. 